Board of Governors of the Federal Reserve System

International Finance Discussion Papers

Number 631

December 1998

updated April 1999

\title{
IDIOSYNCRATIC TASTES IN A TWO-COUNTRY OPTIMIZING MODEL: IMPLICATIONS OF A STANDARD PRESUMPTION
}

Francis E. Warnock

NOTE: International Finance Discussion Papers are preliminary materials circulated to stimulate discussion and critical comment. References in publications to International Finance Discussion Papers (other than an acknowledgment that the writer has had access to unpublished material) should be cleared with the author or authors. Recent IFDPs are available on the Web at www.bog.frb.fed.us. 


\title{
IDIOSYNCRATIC TASTES IN A TWO-COUNTRY OPTIMIZING MODEL: IMPLICATIONS OF A STANDARD PRESUMPTION
}

Francis E. Warnock ${ }^{*}$

\begin{abstract}
International spillovers and exchange rate dynamics are examined in a two-country dynamic optimizing model that allows for idiosyncratic tastes across countries. Specifically, there is a home-good bias in consumption patterns: at given relative prices the ratio of home goods consumed to foreign goods consumed is higher in the home country. The setup nests Obstfeld and Rogoff (1995), who assume identical tastes. Allowing for idiosyncratic tastes produces results that differ from Obstfeld and Rogoff's: expansionary monetary policy increases home relative utility, the international spillovers of a fiscal expansion are reduced, and there are both short-run and long-run deviations from consumption-based purchasing power parity. The model's predictions are broadly consistent with those from the Frenkel, Razin and Yuen (1996) version of the two-country Mundell-Fleming model and with observed behavior of real and nominal exchange rates.
\end{abstract}

Keywords: Home bias, monetary policy, fiscal policy, purchasing power parity.

* This paper, a substantially revised version of my earlier paper entitled "Globalization, Insularity and the International Spillovers of Macroeconomic Policies," was written while I was a Student Intern in the International Finance Division of the Federal Reserve Board and a Ph.D. candidate at the University of North Carolina at Chapel Hill. I thank Stanley Black, May Hagiwara, and Dale Henderson for guidance; Jon Faust, John Rogers, and Michael Salemi for helpful comments; and participants at the UNC Money/Macro Seminar, the 1997 Southeastern Economic Theory and International Economics Conference, and the workshop at the International Finance Division of the Board of Governors of the Federal Reserve System. The April 1999 update was motivated in part by a discussion with Cedric Tille, whom I also thank. The views in this paper are solely the responsibility of the author and should not be interpreted as reflecting the views of the Board of Governors of the Federal Reserve System or of any other person associated with the Federal Reserve System. E-mail: warnock@email.unc.edu 


\section{Introduction}

Open-economy macroeconomics has long relied on the workhorse Mundell-Fleming (MF) model to analyze the impacts of monetary and fiscal policies. More recently, the development of openeconomy models with optimizing agents has cast doubt on the robustness of the MF model without providing a tractable alternative for policy analysis that broadly replicates the basic MF results. If a simple optimizing model can be constructed that replicates many of the results of the MF model, and provides plausible explanations when the results differ, then in the near future optimizing-agent models may indeed become a more important part of the practitioners toolkit.

A key component of the MF model is the assumption of sticky prices. Obstfeld and Rogoff (OR) in their pathbreaking 1995 article introduce sticky prices into a two-country dynamic optimizing model with imperfect competition, but the results they obtain do not resemble those of Mundell $(1963,1968)$ and Fleming (1962). Casual observation suggests that consumption is highly skewed towards domestic goods. Before the relatively recent movement towards models with explicit micro foundations, this home bias in consumption was represented by a marginal propensity to import that was smaller than the marginal propensity to spend on domestic goods. The model in OR, though, assumes that individuals have identical preferences for all goods in the world.

The theoretical model presented in this paper takes a significant step towards reconciling the optimizing framework with the policy conclusions of Mundell and Fleming. It departs from the Obstfeld-Rogoff model by allowing for idiosyncratic tastes, and thereby incorporating the standard presumption of a home bias in consumption. The degree of home bias depends on a parameter in an individual's utility function: as home bias increases, individuals obtain increasingly more utility from domestic goods.

It is shown in this paper that the imposition of identical tastes has strong implications for the results in OR's model. Some of the implications are obvious: with identical tastes, consumption baskets are identical across countries and thus it is not surprising that both relative and absolute consumption-based purchasing power parity (PPP) hold at all times. Other implications are more subtle. For example, with identical preferences and zero initial net foreign assets, a domestic monetary expansion increases utility equally throughout the world. Moreover, the assumption of identical preferences severely limits the real world applicability of optimizing-agent models: insights can be obtained into the cross-country effects of economic policies of countries for whom trade is a large share of GDP, such as Belgium and the Netherlands, but not for relatively closed countries such as the U.S., the European Union as a whole, and Japan.

Macroeconomic models are notoriously poor at replicating two aspects of observed exchange rate behaviort: the extreme volatility of nominal exchange rates and the remarkable persistence of deviations from PPP. The model with home bias does, however, make predictions consistent with these two phenomena. As home bias increases, Dornbusch (1976) type nominal exchange rate overshooting becomes more pronounced -- as long as the elasticity of substitution between consumption and real balances is not unitary. Moreover, after a monetary shock nominal exchange 
rates are more volatile than fundamentals such as price levels and money supplies if there is home bias. $^{1}$

Not surprisingly, with sticky prices and different consumption baskets across countries, short-term deviations from relative PPP are possible. However, it has been observed that deviations from PPP are remarkably persistent, more so than can be explained by sticky prices. ${ }^{2}$ Krugman (1990) offers an explanation: since Home and Foreign residents are likely to exhibit very different spending habits, the wealth transfers brought on by current account imbalances induce significant movements in the real exchange rate. The model presented here makes a qualitatively similar prediction: any asymmetric shock - even a monetary one - results in long-run wealth transfers and, if preferences are idiosyncratic, small long-run deviations from PPP.

Allowing for home bias yields other interesting results. Balanced-budget expansionary fiscal policy abroad has unequivocally positive consumption and output spillovers when, as in OR, there is no home bias: the increased spending falls equally on all goods in the world, thus domestic producers experience increased demand for their products. However, with increased home bias, the positive spillovers diminish. This has particular importance in light of US-Japan trade negotiations: in a world without home bias, if Japan increases government spending (and simultaneously raises taxes) to stimulate its economy, US producers would experience increased demand for their products, and Japan's trade surplus with the US would likely fall. However, if Japanese citizens prefer Japanese goods, the results for US producers and the US trade deficit may be very different. In fact, only a small degree of home bias is necessary to get a result that would be quite unsettling to American trade negotiators: a balanced-budget fiscal expansion in Japan results in an improvement in its current account.

The two-country model presented here forces us to rethink our views on money neutrality. Many economists believe that money is neutral in the long run. In this model money is world neutral: the sole long-run world effect of an increase in world money supply is an increase in prices. But the country-level effects of asymmetric monetary policies are in no way neutral: long-run outputs and consumptions react quite differently across countries.

With the explicit welfare measure that the model is derived from, we are better able to evaluate the welfare effects of monetary policy. A surprising result of the Obstfeld-Rogoff model is that expansionary monetary policy has identical effects on utility throughout the world, regardless of which country actually expands. My model shows that this result hinges on the assumption of identical preferences. With home bias, the country that inflates experiences a greater increase in utility. If individuals prefer foreign goods, a monetary expansion causes utility to increase more

1 Other theoretical models can also reproduce some of the observed features of exchange rates. For example, Hagiwara (1994) shows that the terms of trade is more volatile when preferences are idiosyncratic in a Lucas (1982) type model with complete markets. Devereaux (1997) makes a similar prediction in a pricing-tomarket model with identical preferences.

2 There is vast empirical evidence that deviations from PPP exist and that convergence to PPP is a slow process (See, for example, the review of Froot and Rogoff, 1995). 
abroad. Only in the specific case of identical preferences is the increase in utility identical across countries.

The effects of productivity shocks also depend on the degree of home bias. In particular, the shortrun correlation between the real exchange rate and relative output is positive - as is predicted by many optimizing models - if home bias is slight, but is negative for more pronounced home bias. This is a potential explanation why researchers have had difficulties documenting a positive empirical relationship, as noted by Stockman (1998).

This paper also highlights the restrictions imposed by assuming logarithmic preferences for real balances, or unitary elasticity of substitution between consumption and real balances. As mentioned above, unitary elasticity of substitution between consumption and real balances precludes exchange rate overshooting. Also, short-run real interest rates fall so much when the elasticity of substitution between consumption and real balances is unitary that permanent productivity and fiscal shocks have no effect on short-run world output and consumption.

It is important that the policy conclusions of the dynamic optimizing model are familiar. I show that they are not too different, in a broad sense, from those of a version of the two-country MF model by Frenkel, Razin and Yuen (1996) that emphasizes the role of idiosyncratic tastes. To be sure, the details are quite different, but, reassuringly, the main results are those international economists have been familiar with for decades.

The paper is organized as follows. In Section II the dynamic optimizing model, which completely nests OR, is developed. The supply side of the model is based on the static closed-economy models of Blanchard and Kiyotaki (1987) and Ball and Romer (1989). The demand side derives from a Dixit and Stiglitz (1977) type consumption index. Analytical solutions, obtained by log-linearizing around an initial steady state, are discussed in Section III for monetary, fiscal, and productivity shocks. Section IV compares the up-to-date model developed here to a relatively standard twocountry MF model. Section V concludes.

\section{An Optimizing Model with Idiosyncratic Tastes ${ }^{3}$}

In Section II.A, the structural model is developed. In Section II.B, the equations that govern the long-run, flexible price steady state changes are presented, under the assumption that the countries

\footnotetext{
3 The model is similar to others that have been developed simultaneously. It is most similar to Ghironi (1998), who also allows for idiosyncratic tastes across continents in a U.S.-Europe model and allows governments to balance their budgets intertemporally instead of period-by-period, but imposes logarithmic preferences for real balances. Corsetti and Pesenti (1998), by separating the elasticity of substitution between Home and Foreign goods from the degree of monopolistic competition, are able to get closed-form solutions for a version of OR with logarithmic preferences for real balances, although in doing so assume a two-good world with identical tastes, consumption-based PPP, and unitary elasticity of substitution. These assumptions play prominent roles in Corsetti and Pesenti's results: their two-country model allows for current account imbalances that never occur. Tille (1998) gets around the uncomfortable assumption of PPP by using a pricing-to-market model in which the law of one price does not hold.
} 
are mirror images. The short-run, sticky price deviations from the initial steady state are discussed in Section II.C.

\section{II.A The Structural Model and Initial Steady State}

The world is inhabited by a continuum of producer/consumers each producing a single differentiated product. Prices are sticky, which, in this model with imperfect competition, may be motivated by a 'menu costs' argument as in Mankiw (1985). World population is normalized to one and individuals producer/consumers are indexed by $z \in[0,1]$, with the fractions $n$ and $1-n$ residing in Home and Foreign, respectively. There is no uncertainty except for one-time unanticipated shocks that are either temporary or permanent. Individuals in both countries can freely borrow and lend on world capital markets. Production is not explicitly modeled and there is no physical capital nor investment. For simplicity, it is assumed that output is equal to labor input.

Table 1: A Typical Home Producer/Consumer's Problem

$$
\begin{aligned}
U_{t} & =\sum_{s=t}^{\infty} \beta^{s-t}\left[\log C_{s}+\frac{\chi}{1-\varepsilon}\left(\frac{M_{s}}{P_{s}}\right)^{1-\varepsilon}-\frac{\kappa_{s}}{2} y_{s}(z)^{2}\right] \\
B_{H, t} & +E_{t} B_{F, t}+M_{t}=\left(1+i_{t-1}\right) B_{H, t-1}+\left(1+i_{t-1}^{*}\right) B_{F, t-1}+M_{t-1}+p_{t}(z) y_{t}(z)-P_{t} C_{t}-P_{t} T_{t} \\
G_{t} & =T_{t}+\frac{M_{t}-M_{t-1}}{P_{t}} \\
y^{d}(z) & =n\left(c_{H}(z)+g_{H}(z)\right)+(1-n)\left(c_{H}^{*}(z)+g_{H}^{*}(z)\right) \\
& =n\left(\frac{p(z)}{P}\right)^{-\theta} \alpha(C+G)+(1-n)\left(\frac{p(z)}{E P^{*}}\right)^{-\theta}\left(2-\alpha^{*}\right)\left(C^{*}+G^{*}\right)
\end{aligned}
$$

The problem of a typical Home resident, $z$, is presented in Table 1. She chooses paths for consumption, $C$; money and bond holdings, $M$ and $B$; and effort or output, $y(z)$, to maximize a time separable utility function with unitary elasticity of intertemporal substitution given by (T1.1). ${ }^{4}$ It is assumed that the subjective discount factor, $\beta$, is strictly between zero and one, and the elasticity of substitution between consumption and real balances, $\epsilon$, is greater than zero. Importantly, the setup does not impose $\epsilon=1$, as do models such as Corsetti and Pesenti (1998) and Ghironi (1998) that use logarithmic preferences for real balances. Empirical work using post-WWII panel data suggests $\epsilon$ is around 9; see Koenig (1990). As will be shown, whether $\epsilon$ equals one affects many results; exchange rate overshooting, for example, only occurs if $\epsilon \neq 1$.

\footnotetext{
${ }^{4}$ The money-in-the-utility function approach can be rationalized by arguing that real money balances allow agents to save time in conducting transactions.
} 
In each period $t$ a Home resident faces a budget constraint given by equation (T1.2), which takes into account costless international lending and borrowing. ${ }^{5}$ Governments finance spending by taxes and seignorage, and must balance their budgets in every period; the Home government's budget constraint is given by equation (T1.3). Individuals' budget constraints are immediately affected by changes in government policy: if the money supply is not increased, increases in government spending are matched by increases in lump-sum taxes, $T$, whereas increases in the money supply with no change in government spending result in lump-sum transfer payments. A Home producer, $z$, takes as given world demand for her product, defined as a population weighted average of Home and Foreign private and public demands, given by equation (T1.4).

Table 2. A Home Consumer's Consumption Index

$$
\begin{aligned}
& C=\left[\int_{0}^{n} \alpha^{1 / \theta}\left(c_{H}(z)\right)^{\frac{\theta-1}{\theta}} d z+\int_{n}^{1}(2-\alpha)^{1 / \theta}\left(c_{F}(z)\right)^{\frac{\theta-1}{\theta}} d z\right]^{\frac{\theta}{\theta-1}} \\
& c_{H}(z)=\alpha(p(z) / P)^{-\theta} C, \quad z \in[0, n] \\
& c_{F}(z)=(2-\alpha)\left[\frac{E p^{*}(z)}{P}\right]^{-\theta} C, \quad z \in(n, 1]
\end{aligned}
$$

In Table 2, which shows the consumption index and demand functions for Home and Foreign goods, $p(z)$ and $p^{*}(z)$ are prices of a good $z \in[0, \mathrm{n}]$ produced in Home and a good $\mathrm{z} \in(\mathrm{n}, 1]$ produced in Foreign, respectively; $E$ is the Home currency price of Foreign currency; $P$ is the consumption-based price index; and the law of one price is assumed to hold. ${ }^{6}$ Idiosyncratic tastes are introduced through a parameter in the consumption index, equation (T2.1), which is a modification of the Dixit and Stiglitz (1977) constant elasticity of substitution form. Specifically, there is a home-good bias in consumption patterns if at given relative prices the ratio of Home goods consumed to Foreign goods consumed is higher in Home. A Home consumer's demand functions for Home and Foreign goods, equations (T2.2) and (T2.3), derived by minimizing the cost of one unit of composite consumption taking product prices as given, is shown to depend on the home bias parameter, $\alpha(\alpha \in(0,2))$, and relative prices. ${ }^{7}$ The intratemporal substitution elasticity between Home and Foreign goods, $\theta$, is

5 The stocks of Home and Foreign bonds held by Home residents entering period $t+1$ is $B_{H, t}$ and $B_{F, t}$, respectively. The nominal interest rates, $i_{t}$ and $i_{t}{ }^{*}$, are defined as the interest rates earned between $t$ and $t+1$. The zero net bond condition imposes $n B_{t}+(1-n) B_{t}^{*}=0$, where $B_{t}=B_{H, t}+E_{t} B_{F, t}$ and $B_{t}^{*}=B_{H, t}^{*} / E_{t}+B_{F, t}^{*}$.

6 The price index may be interpreted as the cost of one unit of consumption and is given by

$$
P=\left(\int_{0}^{n} \alpha p(z)^{1-\theta} d z+\int_{n}^{1}(2-\alpha)\left[E p^{*}(z)\right]^{1-\theta} d z\right)^{\frac{1}{1-\theta}}
$$

See Obstfeld and Rogoff (1996), pages 222-228, for a complete description of price indices.

7 The range for $\alpha$ was chosen merely to nest Obstfeld and Rogoff's model. Any other non-negative range can be used without affecting the dynamics of the model. 
also the price elasticity of demand faced by each producer, and is assumed to be greater than one to ensure that marginal revenue is positive. Real Home government consumption spending, $G$, is derived analogously to private Home consumption spending, and governments are assumed to have the same bias parameter as consumers. ${ }^{8}$

From Table 2, the relative demand of a Home consumer for Home goods is

$$
\frac{c_{H}}{c_{F}}=\left(\frac{\alpha}{2-\alpha}\right)\left(\frac{p}{E p^{*}}\right)^{-\theta}
$$

where $p$ and $p^{*}$ are the prices of the typical Home and Foreign good, respectively. ${ }^{9}$ If $\alpha>1$, there is a home bias in consumption; that is, for any given relative price, Home consumers will always demand relatively more Home goods than will Foreign consumers. This does not imply Home consumers will always demand more Home than Foreign goods: with high enough relative prices a Home consumer, even with a home bias, will demand more imported than domestic goods.

Home bias is shown graphically in Figure 1, which depicts the effect of home bias on a consumer's choice between domestic and imported goods and is drawn for unitary relative prices. Utility curve $\mathrm{u}_{\mathrm{A}}$ and income-consumption path OA represents the Obstfeld-Rogoff case in which consumers have identical preferences for all goods regardless of origin: with unitary relative prices, consumers demand equal amounts of domestic and imported goods. Consumers with a home bias $(\alpha=1.6$ in this case) have utility curve $\mathrm{u}_{\mathrm{B}}$ and income-consumption path $\mathrm{OB}$; with unitary relative prices their relative demand for domestic goods is $\alpha /(2-\alpha)$, or four.

The first-order conditions from a typical Home individual's dynamic maximization problem are given in Table 3; Foreign individuals have analogous first-order conditions. Equation (T3.1) is the standard first-order consumption Euler equation for unitary elasticity of intertemporal substitution. The consumption-based money demand equation, (T3.2), equates the marginal utility of real balances to the opportunity cost in terms of consumption, and reflects the fact that at the margin in period $t$ individuals must be indifferent between consuming one unit of $C$ and using the same funds to raise cash balances. Equation (T3.3) is the labor-leisure tradeoff: the marginal utility of the additional revenue earned from producing an extra unit of the Home good must equal the marginal disutility of the needed effort. Equation (T3.4) is a real uncovered interest parity condition; both real and nominal uncovered interest parity hold in this model. ${ }^{10}$

\footnotetext{
8 The Home government's demand for a good $z$ produced by a Home resident is given by $g_{H}(z)=\alpha(p(z) / P)^{-\theta} G, \quad z \in[0, n]$.
}

It is reasonable to allow governments to have higher home biases than private individuals. However, this would require another consumption-based price index, which would likely complicate the model more than is justified.

9 Since all individuals in a country are symmetric and choose the same price and output in equilibrium, the $z$ denotation can be dropped. The price and output of the typical Home good are denoted by $p$ and $y$, respectively.

10 The Home real interest rate and nominal UIP condition in this perfect foresight model are given by

$$
1+i_{t} \equiv \frac{P_{t+1}}{P_{t}}\left(1+r_{t}\right) \quad \text { and } \quad 1+i_{t}=\frac{E_{t+1}}{E_{t}}\left(1+i_{t}^{*}\right) .
$$


Table 3: First-Order Conditions

$$
\begin{aligned}
C_{t+1} & =\beta C_{t}\left(1+r_{t}\right) \\
\frac{M_{t}}{P_{t}} & =\left[\chi C_{t} \frac{1+i_{t}}{i_{t}}\right]^{1 / \varepsilon} \\
y_{t}^{\theta+1} & =\left(\frac{\theta-1}{\theta \kappa_{t}}\right)^{\theta} C_{t}^{-\theta}\left[n \alpha\left(C_{t}+G_{t}\right)+(1-n)\left(\frac{E_{t} P_{t}^{*}}{P_{t}}\right)^{\theta}\left(2-\alpha^{*}\right)\left(C_{t}^{*}+G_{t}^{*}\right)\right] \\
1+r_{t} & =\frac{Q_{t+1}}{Q_{t}}\left(1+r_{t}^{*}\right)
\end{aligned}
$$

Steady-state solutions are presented in Table 4. It is not possible to get closed-form solutions for steady-state consumption and output if I allow for both non-identical preferences and different country sizes. In order to concentrate on the effect of home bias, I assume the countries are mirror images: they have equal sizes $(n=1-n=1 / 2)$ and identical bias parameters $\left(\alpha=\alpha^{*}\right)$. The mirror image assumption has as a special case identical preferences but in general allows for home bias.

Table 4: Steady State Solutions

$$
\begin{aligned}
& \bar{r}=\frac{1-\beta}{\beta} \\
& \bar{C}=\bar{r} \bar{B}+\frac{\bar{p} \bar{y}}{\bar{P}}-\bar{G} \\
& \bar{C}^{*}=-\bar{r}\left(\frac{n}{1-n}\right) \frac{\bar{P}}{\bar{E} \bar{P}^{*}} \bar{B}+\frac{\bar{p}^{*} \bar{y}^{*}}{\bar{P}^{*}}-\bar{G}^{*}
\end{aligned}
$$

Initial Steady State Assumptions

$$
\begin{aligned}
& \bar{B}_{0}=\bar{B}_{0}^{*}=0 \\
& \bar{G}_{0}=\bar{G}_{0}^{*}=0
\end{aligned}
$$

Initial Steady State Levels

$$
\begin{aligned}
& \bar{y}_{0}=\bar{y}_{0}^{*}=\left(\frac{\theta-1}{\theta \bar{\kappa}}\right)^{1 / 2}=\bar{C}_{0}=\bar{C}_{0}^{*} \\
& \frac{\bar{M}_{0}}{\bar{P}_{0}}=\frac{\bar{M}_{0}^{*}}{\bar{P}_{0}^{*}}=\left(\frac{\chi}{1-\beta}\right)^{1 / \varepsilon} \bar{y}_{0}{ }^{1 / \varepsilon}=\left(\frac{\chi}{1-\beta}\right)^{1 / \varepsilon} \bar{C}_{0}{ }^{1 / \varepsilon}
\end{aligned}
$$

In solving for the steady state it is assumed that all exogenous variables are constant. This, in turn, implies a constant steady-state consumption level, which, by the consumption Euler, equation (T3.1), implies a constant steady-state real interest rate, given by equation (T4.1). In the steady state the intertemporal budget constraints are given by equations (T4.2) and (T4.2*). It is assumed in the 
initial steady state net foreign assets and government spending are zero. ${ }^{11}$ From (T4.2) and (T4.2*), in the initial steady state consumption equals output, and is given by (T4.3), which follows from the labor-leisure tradeoff (T3.3). Initial steady state real balances are given by equation (T4.4), which shows that $1 / \epsilon$ is the elasticity of substitution between consumption and real balances.

The model is solved under the mirror image assumption of equal country sizes and bias parameters. In general, the solution method is to derive expressions for cross-country differences and world weighted averages, where a world weighted average for any variable $X$ is given by

$X_{t}^{W}=n X_{t}+(1-n) X_{t}^{*}=\frac{1}{2}\left(X_{t}+X_{t}^{*}\right)$

It is important to define two terms, the CPI-based real exchange rate, $Q$, and the terms of trade, $t$.

$Q_{t} \equiv \frac{E_{t} P_{t}^{*}}{P_{t}}, \quad t_{t} \equiv \frac{p_{t}}{p_{t}^{*} E_{t}}$

where small $p$ and $p^{*}$ are product prices of typical Home and Foreign goods, and large $P$ and $P^{*}$ are CPIs. As defined an increase in $Q$ is a real depreciation for the Home currency, and an increase in $t$ is an improvement in Home's terms of trade.

\section{The Nature of Shocks and Price Stickiness}

To analyze the effects of policy changes and productivity shocks on Home and Foreign variables, the model is linearized around the initial steady state. This is done, as in OR, by expressing the model in terms of deviations from the baseline steady-state path. In the policy experiments conducted in this paper, one-time unanticipated shocks to the money supply, government spending, or productivity push the economy off its steady state path. The shocks are level shifts that occur in period $t$ and are either temporary (lasting one period) or permanent.

Price stickiness is introduced by assuming producers must set their prices before they observe the shock: for the first period of a shock, $t$, product prices are constant, but thereafter, in periods $t+1$ and beyond, product prices fully adjust and a new steady state is reached. There are, thus, two types of deviations from the initial steady state. Long-run deviations are those consistent with flexible product prices and are changes from the initial to a new steady state. These long-run steady-state changes are denoted by tildes; for any variable $X, \tilde{X} \equiv d \bar{X} / \bar{X}_{0}$, where $\bar{X}_{0}$ is the initial steady-state value. In the short run when product prices are fixed, the economies are not on a steady-state path. Short-run deviations from the initial steady state are denoted by hats; for any variable $X$, $\hat{X} \equiv d X_{t} / \bar{X}_{0}$, where $t$ is the period of the shock.

${ }^{11}$ Note that the mirror image assumption and the assumptions made to get an initial, closed form steady state together imply that $\bar{p}_{0}=\bar{E}_{0} \bar{p}_{0}^{*}, \bar{p}_{0}=\bar{P}_{0}$ and $\bar{p}_{0}^{*}=\bar{P}_{0}^{*}$. 


\section{II.B Long-Run Steady-State Changes}

Long-run equations are presented in Table 5a. Log-linearizing the Home CPI -- found in footnote 6 -- and its Foreign counterpart around the initial steady state gives equations (T5a.1) and (T5a.1 ${ }^{*}$ ). The log-linearized versions of (T1.4) and its Foreign counterpart, interpreted as world demand schedules for typical home and foreign products, are given by equations (T5a.2) and (T5a.2*). Equation (T3.3) and its foreign counterpart, which describe the optimal flexible-price output levels, are approximated by equations (T5a.3) and (T5a.3*). Linearizing (T4.2) and (T4.2 ${ }^{*}$ ), the intertemporal budget constraints, around the initial steady state yields equations (T5a.4) and (T5a. $4^{*}$ ). Near the initial steady-state path the consumption Euler equations, (T3.1) and its foreign counterpart, take the log-linear forms (T5a.5) and (T5a.5*) and provide a link between the long and short runs.

Table 5a: Long-Run Equations

$$
\begin{aligned}
& \tilde{P}=\frac{\alpha}{2} \tilde{p}+\left(1-\frac{\alpha}{2}\right)\left(\tilde{E}+\tilde{p}^{*}\right) \\
& \tilde{P}^{*}=\left(1-\frac{\alpha}{2}\right)(\tilde{p}-\tilde{E})+\frac{\alpha}{2} \tilde{p}^{*} \\
& \tilde{y}=-\theta \tilde{p}+\frac{\alpha}{2}\left(\theta \tilde{P}+\tilde{C}+\frac{d \bar{G}}{\bar{y}_{0}}\right)+\left(1-\frac{\alpha}{2}\right)\left(\theta\left(\tilde{E}+\tilde{P}^{*}\right)+\tilde{C}^{*}+\frac{d \bar{G}^{*}}{\bar{y}_{0}}\right) \\
& \tilde{y}^{*}=-\theta \tilde{p}^{*}+\left(1-\frac{\alpha}{2}\right)\left(\theta(\tilde{P}-\tilde{E})+\tilde{C}+\frac{d \bar{G}}{\bar{y}_{0}}\right)+\frac{\alpha}{2}\left(\theta \tilde{P}^{*}+\tilde{C}^{*}+\frac{d \bar{G}^{*}}{\bar{y}_{0}}\right) \\
& (\theta+1) \tilde{y}=-\theta \tilde{\kappa}-\theta \tilde{C}+\frac{\alpha}{2}\left(\tilde{C}+\frac{d \bar{G}}{\bar{y}_{0}}\right)+\left(1-\frac{\alpha}{2}\right)\left(\theta \tilde{Q}+\tilde{C}^{*}+\frac{d \bar{G}^{*}}{\bar{y}_{0}}\right) \\
& (\theta+1) \tilde{y}^{*}=-\theta \tilde{\kappa}^{*}-\theta \tilde{C}^{*}+\left(1-\frac{\alpha}{2}\right)\left(-\theta \tilde{Q}+\tilde{C}+\frac{d \bar{G}}{\bar{y}_{0}}\right)+\frac{\alpha}{2}\left(\tilde{C}^{*}+\frac{d \bar{G}^{*}}{\bar{y}_{0}}\right) \\
& \tilde{C}^{=}=\frac{\bar{r}}{\bar{y}_{0}} d \bar{B}+\tilde{p}+\tilde{y}-\tilde{P}-\frac{d \bar{G}}{\bar{y}_{0}} \\
& \tilde{C}^{*}=-\frac{n}{1-n} \frac{\bar{r}}{\bar{y}_{0}^{*}} d \bar{B}+\tilde{p}^{*}+\tilde{y}^{*}-\tilde{P}^{*}-\frac{d \bar{G}^{*}}{\bar{y}_{0}^{*}} \\
& \tilde{C}^{*}=(1-\beta) \hat{r}+\hat{C} \\
& \tilde{C}^{*}=(1-\beta) \hat{r}^{*}+\hat{C}^{*} \\
& \tilde{M}^{*}-\tilde{P}=\frac{\tilde{C}}{\varepsilon} \\
& \tilde{M}^{*}-\tilde{P}^{*}=\frac{\tilde{C}^{*}}{\varepsilon}
\end{aligned}
$$

Long-run linearized versions of the money demand equations (T4.4) and its foreign counterpart are given by equations (T5a.6) and (T5a.6*), which use the fact that across steady states real interest rates and inflation rates do not change. Note that money demand depends on consumption, a prediction common to many intertemporal monetary models. In this model consumption is roughly equivalent to disposable income. 
Long-run cross-country differences of the equations in Table $5 \mathrm{a}$ are presented in Table $5 \mathrm{~b}$. Subtracting the long-run CPI equations, (T5a.1) and (T5a. $1^{*}$ ), and using the definitions of the real exchange rate and terms of trade, yields equation (T5b.1), which shows that if preferences are identical $(\alpha=1)$ the long-run real exchange rate is constant and PPP holds for any shock.

Table 5b: Long-Run Equations - Cross-Country Differences

$$
\begin{aligned}
& \tilde{Q}=(1-\alpha) \tilde{t} \\
& \tilde{y}-\tilde{y}^{*}=-\alpha(2-\alpha) \theta \tilde{t}+(\alpha-1)\left(\tilde{C}-\tilde{C}^{*}\right)+(\alpha-1)\left(d \bar{G}-d \bar{G}^{*}\right) / \bar{y}_{0} \\
& (\theta+1)\left(\tilde{y}-\tilde{y}^{*}\right)=-\theta\left(\tilde{\kappa}-\tilde{\kappa}^{*}\right)+(\alpha-\theta-1)\left(\tilde{C}-\tilde{C}^{*}\right)-(2-\alpha)(\alpha-1) \theta \tilde{t}+(\alpha-1) \frac{d \bar{G}-d \bar{G}^{*}}{\bar{y}_{0}} \\
& \left(\tilde{C}-\tilde{C}^{*}\right)=\frac{2 \bar{r} d \bar{B}}{\bar{y}_{0}}+(2-\alpha) \tilde{t}+\left(\tilde{y}-\tilde{y}^{*}\right)-\frac{d \bar{G}-d \bar{G}^{*}}{\bar{y}_{0}} \\
& \tilde{C}-\tilde{C}^{*}=\left(\hat{C}-\hat{C}^{*}\right)+(\tilde{Q}-\hat{Q}) \\
& \left(\tilde{M}-\tilde{M}^{*}\right)-\left(\tilde{P}-\tilde{P}^{*}\right)=\frac{1}{\varepsilon}\left(\tilde{C}-\tilde{C}^{*}\right)
\end{aligned}
$$

From equation (T5b.2), it is clear how the bias parameter, $\alpha$, affects relative demand. If tastes are identical across countries, demand differences are affected by only the terms of trade: as Home products become expensive relative to Foreign ones, demand switches from Home to Foreign. If individuals prefer domestic goods, however, spending differentials - both private and public - matter to a degree that depends on $\alpha$. Moreover, the terms of trade influences demand less as $\alpha$ increases: if citizens have an inherent preference for domestic goods, relative prices matter somewhat less.

Equation (T5b.3) shows that long-run supply differentials are affected by differences in productivity and consumption as well as, in contrast to OR, changes in the terms of trade. A permanent increase in the relative marginal disutility of effort reduces Home relative supply, as expected. ${ }^{12}$ An increase in relative consumption allows Home individuals to enjoy relatively more leisure, thus relative supply falls. An improvement in Home terms of trade reduces relative supply if $\alpha>1$.

Subtracting the log-linearized intertemporal budget constraints yields equations for long-run crosscountry consumption differentials, equation (T5b.4). The effect of changes in the terms of trade on consumption differentials is maximum when $\alpha=1$ : relative income changes matter most when imported goods carry heavy weights in the consumption basket. Subtracting the log-linearized consumption Eulers yields equation (T5b.5), which provides a link between the short and long runs, and shows that consumption differentials are permanent for any shock only if the real exchange rate is constant.

Subtracting the log-linearized long-run money demand equations yield equation (T5b.6). If $\epsilon=1$, the long-run change in relative consumption equals the long-run change in relative real balances; in the

\footnotetext{
${ }^{12}$ Recall that $\kappa$ is the marginal disutility of effort; an increase in $\kappa$ can therefore be interpreted as a decrease in productivity.
} 
more general and empirically relevant case of $\epsilon>1$, the change in relative consumption is greater than the change in real balances.

Long-run world weighted averages are presented in Table 5c. Long-run changes in world CPI equal long-run changes in product prices (T5c.1). Equation (T5c.2) shows that changes in long-run world demand equals changes in long-run world private and public spending, as expected. From equation (T5c.3), a long-run, negative world supply shock (an increase in the marginal disutility of effort, $\kappa$ ) lowers world output as effort becomes increasingly onerous.

Table 5c: Long-Run Equations - World Weighted Averages

$$
\begin{aligned}
& \tilde{P}^{W}=\tilde{p}^{W} \\
& \tilde{y}^{W}=\tilde{C}^{W}+d \bar{G}^{W} / \bar{y}_{0} \\
& (\theta+1) \tilde{y}^{W}=-\theta \tilde{\kappa}^{W}+(1-\theta) \tilde{C}^{W}+d \bar{G}^{W} / \bar{y}_{0} \\
& \tilde{C}^{W}=\hat{C}^{W}+(1-\beta) \hat{r}^{W} \\
& \tilde{M}^{W}-\tilde{P}^{W}=\tilde{C}^{W} / \varepsilon
\end{aligned}
$$

Summing the consumption Euler equations gives equation (T5c.4). Consumption shocks are permanent only if real interest rates are, on average, unchanged. In general, a decrease in short-run real interest rates -- caused, for example, by an increase in world money supply -- allows world consumption to be slightly higher in the short run than in the long run. From equation (T5c.5), the long-run increase in world consumption is proportional to the increase in world real balances.

\section{II.C. Short-Run Deviations from the Initial Steady State}

Short-run deviations from the initial steady state are presented in Table 6a. In the short run nominal product prices, $p$ and $p^{*}$, are fixed, so changes in CPIs, (T6a.1) and (T6a.1 ${ }^{*}$ ), depend solely on changes in the exchange rate. With preset prices, the equations equating marginal revenue and marginal cost, (T3.3), need not hold; short-run output is determined entirely by demand equations (T6a.2) and (T6a.2*). Equations for Home and Foreign current accounts yield equations (T6a.3) and (T6a.3*), which show that Home individuals must forego some consumption to lend in the short run. ${ }^{13}$ Log-linearizing the money demand equations, (T3.2) and its foreign counterpart, and noting

13 The short-run Home current account surplus is

$$
B_{t}-B_{t-1}=r_{t-1} B_{t-1}+p_{t} y_{t} / P_{t}-C_{t}-G_{t}
$$

This is the amount lent to Foreign in the short run, which is repaid with interest in the long run when current accounts are required to be balanced.

The change in net foreign assets in equations (T6a.3) and (T6a.3*) is a long-run steady-state change because in the special case of an initial steady state with zero net foreign assets, the short-run and long-run changes in the net foreign asset position are identical. 
that all $(t+1)$ subscripts are steady-state changes (tildes) and all $t$ subscripts are short-run changes (hats), gives equations (T6a.4) and (T6a.4*).

Table 6a: Short-Run Equations

$$
\begin{aligned}
& \hat{P}=\left(1-\frac{\alpha}{2}\right) \hat{E} \\
& \hat{P}^{*}=-\left(1-\frac{\alpha}{2}\right) \hat{E} \\
& \hat{y}=\frac{\alpha}{2}\left(\theta \hat{P}+\hat{C}+\frac{d G_{t}}{\bar{y}_{0}}\right)+\left(1-\frac{\alpha}{2}\right)\left(\theta\left(\hat{E}+\hat{P}^{*}\right)+\hat{C}^{*}+\frac{d G_{t}^{*}}{\bar{y}_{0}}\right) \\
& \hat{y}^{*}=\left(1-\frac{\alpha}{2}\right)\left(\theta(\hat{P}-\hat{E})+\hat{C}+\frac{d G_{t}}{\bar{y}_{0}}\right)+\frac{\alpha}{2}\left(\theta \hat{P}^{*}+\hat{C}^{*}+\frac{d G_{t}^{*}}{\bar{y}_{0}}\right) \\
& \frac{d \bar{B}}{\bar{y}_{0}}=\hat{y}-\hat{P}-\hat{C}-\frac{d G_{t}}{\bar{y}_{0}} \\
& -\frac{d \bar{B}}{\bar{y}_{0}}=\hat{y}^{*}-\hat{P}^{*}-\hat{C}^{*}-\frac{d G_{t}^{*}}{\bar{y}_{0}} \\
& \hat{M}-\hat{P}=\frac{\hat{C}}{\varepsilon}-\frac{\beta}{\varepsilon}\left(\frac{\tilde{P}-\hat{P}}{1-\beta}+\hat{r}\right) \\
& \hat{M}^{*}-\hat{P}^{*}=\frac{\hat{C}^{*}}{\varepsilon}-\frac{\beta}{\varepsilon}\left(\frac{\tilde{P}^{*}-\hat{P}^{*}}{1-\beta}+\hat{r}^{*}\right)
\end{aligned}
$$

Table $6 \mathrm{~b}$ contains equations for short-run cross-country differences. Equation (T6b.1), the short-run change in the real exchange rate, shows that in this model as home bias increases, the correlation between real and nominal exchange rates increases and nominal exchange rates become much more volatile than price indices. ${ }^{14}$ Moreover, only with home bias does the nominal exchange rate deviate from its PPP-level in the short run.

Short-run output differentials -- recall, output is demand determined in the short run -- are given by equation (T6b.2). As in the long run, private and public spending differentials affect output differentials only if preferences are idiosyncratic: with home bias more spending stays at home and spending differentials matter. Note, too, that the demand-switching effect of nominal exchange rate changes is maximum when $\alpha=1$ and decreases as $\alpha$ increases.

Table 6b: Short-Run Equations - Cross-Country Differences

$$
\begin{aligned}
& \hat{Q}=(\alpha-1) \hat{E} \\
& \hat{y}-\hat{y}^{*}=\alpha(2-\alpha) \theta \hat{E}+(\alpha-1)\left(\hat{C}-\hat{C}^{*}\right)+(\alpha-1)\left(d G_{t}-d G_{t}^{*}\right) / \bar{y}_{0}
\end{aligned}
$$

${ }^{14}$ To see that the nominal exchange rate is more volatile than relative prices when there is home bias, note that (T6b.1) implies that $\hat{P}-\hat{P}^{*}=(2-\alpha) \hat{E}$. If $\alpha=1.8$, nominal exchange rate changes are five times greater than changes in relative prices. MacDonald (1988) provides empirical evidence of this. 


$$
\begin{aligned}
& \left(\hat{C}-\hat{C}^{*}\right)=-\frac{2 d \bar{B}}{\bar{y}_{0}}-(2-\alpha) \hat{E}+\left(\hat{y}-\hat{y}^{*}\right)-\left(d G_{t}-d G_{t}^{*}\right) / \bar{y}_{0} \\
& \left(\hat{M}-\hat{M}^{*}\right)-(2-\alpha) \hat{E}=\frac{1}{\varepsilon}\left(\hat{C}-\hat{C}^{*}\right)-\frac{1}{\bar{r} \varepsilon}(\tilde{E}-\hat{E}) \\
& \hat{r}-\hat{r}^{*}=\frac{\tilde{Q}-\hat{Q}}{1-\beta}
\end{aligned}
$$

Recall one equation for short-run changes in consumption differentials was given by the consumption Euler equations in Table 5b. Another equation for consumption differentials, (T6a.3), derived by subtracting the equations for Home and Foreign current accounts, shows that the partial effect of a tax-financed one-unit increase in Home relative government spending is to decrease Home relative consumption by one-unit. Note, however, that the crowding out is not quite so severe, especially if there is home bias: from equation (T6a.2) an increase in relative government spending also increases relative output, which in turn has a positive effect on relative consumption. Relative money demand is given by Equation (T6b.4), and equation (6b.5) shows the relationship between the short-run real interest rate differential and real exchange rate dynamics.

Table 6c shows the short-run world weighted averages. Short-run changes in CPIs (T6c.1) are offsetting: with fixed product prices, the short-run changes in CPIs are due solely to changes in the nominal exchange rate, and are therefore equal and opposite across countries. Short-run changes in output equal short-run changes in private and public spending (T6c.2). Equation (T6c.3), which takes into account equation (T6c.1), shows the negative relationship between real interest rates and world money supply.

Table 6c: Short-Run Equations - World Weighted Averages

$$
\begin{aligned}
& \hat{P}^{W}=0 \\
& \hat{y}^{W}=\hat{C}^{W}+d G_{t}^{W} / \bar{y}_{0} \\
& \varepsilon \hat{M}^{W}=\hat{C}^{W}-\frac{\tilde{P}^{W}}{\bar{r}}-\beta \hat{r}^{W}
\end{aligned}
$$

\section{The Dynamic Responses to Policy and Productivity Shocks}

The equations that form the basis for solving the model -- long-run semi-reduced form equations and the MM and GG schedules -- are presented in Section III.A The effects of monetary, fiscal, and productivity shocks are separately investigated in Sections III.B, III.C and III.D, respectively. Since the effects of shocks are additive, nothing is lost with this approach. All equations and solutions were verified numerically in GAUSS for various parameter values.

\section{III.A. Long-Run Semi-Reduced Form Equations and MM and GG Curves}

To derive long-run semi-reduced form equations, equate demand and supply for both Home, equations (T5a.2) and (T5a.3), and Foreign, equations (T5a.2 ${ }^{*}$ ) and (T5a. $3^{*}$ ), to eliminate $\tilde{y}$ and $\tilde{y}^{*}$ and get the following equations: 


$$
\begin{aligned}
& (\alpha-2 \theta) \tilde{C}+(2-\alpha) \tilde{C}^{*}+\theta(2-\alpha) \tilde{Q}=-(\theta+1) \frac{\bar{r} d \bar{B}}{\bar{y}_{0}}+(\theta-\alpha+1) \frac{d \bar{G}}{\bar{y}_{0}}-(2-\alpha) \frac{d \bar{G}^{*}}{\bar{y}_{0}}-(1-\theta) \tilde{\kappa} \\
& (\alpha-2 \theta) \tilde{C}^{*}+(2-\alpha) \tilde{C}-\theta(2-\alpha) \tilde{Q}=(\theta+1) \frac{\bar{r} d \bar{B}}{\bar{y}_{0}}+(\theta-\alpha+1) \frac{d \bar{G}^{*}}{\bar{y}_{0}}-(2-\alpha) \frac{d \bar{G}}{\bar{y}_{0}}-(1-\theta) \tilde{\kappa}^{*}
\end{aligned}
$$

Table 7a shows the long-run semi-reduced form equations for consumption and output. Solving the above two equations simultaneously gives long-run semi-reduced form equations for consumption (T7a.1) and (T7a.1*). Long-run semi-reduced form equations for output, (T7a.2) and (T7a.2*), are derived analogously; begin by equating supplies and demands to eliminate $\tilde{C}$ and $\tilde{C}^{*}$.

Table 7a: Long-Run Semi-Reduced Forms

$$
\begin{aligned}
& 2(1-\alpha+\theta) \tilde{C}-\theta(2-\alpha) \tilde{Q}=(\theta+1) \frac{\bar{r} d \bar{B}}{\bar{y}_{0}}+\left(\frac{3 \alpha}{2}-\theta-2\right) \frac{d \bar{G}}{\bar{y}_{0}}-\left(1-\frac{\alpha}{2}\right) \frac{d \bar{G}^{*}}{\bar{y}_{0}}+\left(\frac{\alpha}{2}-\theta\right) \tilde{\kappa}-\left(1-\frac{\alpha}{2}\right) \tilde{\kappa}^{*} \\
& 2(1-\alpha+\theta) \tilde{C}^{*}+\theta(2-\alpha) \tilde{Q}=-(\theta+1) \frac{\bar{r} d \bar{B}}{\bar{y}_{0}}+\left(\frac{3 \alpha}{2}-\theta-2\right) \frac{d \bar{G}^{*}}{\bar{y}_{0}}-\left(1-\frac{\alpha}{2}\right) \frac{d \bar{G}}{\bar{y}_{0}}+\left(\frac{\alpha}{2}-\theta\right) \tilde{\kappa}^{*}-\left(1-\frac{\alpha}{2}\right) \tilde{\kappa} \\
& 4(\theta+1) \tilde{y}=4(\alpha-\theta+1) \tilde{C}+2 \theta(2-\alpha) \tilde{Q}+(3 \alpha-2) \frac{d \bar{G}}{\bar{y}_{0}}+(2-\alpha) \frac{d \bar{G}^{*}}{\bar{y}_{0}}+(\alpha-2-4 \theta) \tilde{\kappa}-(2-\alpha) \tilde{\kappa}^{*} \\
& 4(\theta+1) \tilde{y}^{*}=4(\alpha-\theta+1) \tilde{C}^{*}-2 \theta(2-\alpha) \tilde{Q}+(3 \alpha-2) \frac{d \bar{G}^{*}}{\bar{y}_{0}}+(2-\alpha) \frac{d \bar{G}}{\bar{y}_{0}}+(\alpha-2-4 \theta) \tilde{\kappa}^{*}-(2-\alpha) \tilde{\kappa}
\end{aligned}
$$

Table $7 \mathrm{~b}$ contains cross-country differences of long-run semi-reduced form equations that hold for any shock and can be used to examine the effects of net foreign assets, fiscal policies and productivity shocks on relative consumption (T7b.1), relative output (T7b.2) and the terms of trade (T7b.3). Although care must be taken when interpreting these partial relationships, some intuition can be gleaned from them.

Table 7b: Long-Run Semi-Reduced Forms - Cross-Country Differences

$$
\begin{aligned}
& (1-\alpha+\theta)\left(\tilde{C}-\tilde{C}^{*}\right)=\theta(2-\alpha) \tilde{Q}+(\theta+1) \frac{\bar{r} d \bar{B}}{\bar{y}_{0}}-\frac{\theta-2 \alpha+3}{2 \bar{y}_{0}}\left(d \bar{G}-d \bar{G}^{*}\right)-\frac{\theta-1}{2}\left(\tilde{\kappa}-\tilde{\kappa}^{*}\right) \\
& \tilde{y}-\tilde{y}^{*}=\frac{1}{1+\theta}\left[-(\theta+1-\alpha)\left(\tilde{C}-\tilde{C}^{*}\right)-(2-\alpha)(\alpha-1) \theta \tilde{t}+(\alpha-1) \frac{d \bar{G}-d \bar{G}^{*}}{\bar{y}_{0}}-\theta\left(\tilde{\kappa}-\tilde{\kappa}^{*}\right)\right] \\
& \tilde{t}=\frac{1}{(2-\alpha)(\alpha \theta+1)}\left(\alpha\left(\tilde{C}-\tilde{C}^{*}\right)+(\alpha-1) \frac{d \bar{G}-\overline{d G}{ }^{*}}{\bar{y}_{0}}+\left(\tilde{\kappa}-\tilde{\kappa}^{*}\right)\right) \\
& =\frac{1}{(2-\alpha)(1-\alpha+\alpha \theta)}\left(-\alpha\left(\tilde{y}-\tilde{y}^{*}\right)+(\alpha-1) \frac{d \bar{G}-\bar{d} \bar{G}^{*}}{\bar{y}_{0}}-(\alpha-1)\left(\tilde{\kappa}-\tilde{\kappa}^{*}\right)\right)
\end{aligned}
$$

Equation (T7b.1) shows that a wealth transfer increases relative consumption, but by less than the change in relative net foreign asset positions: Home individuals take advantage of the increased wealth to both increase consumption and reduce their work effort. Not surprisingly, an increase in relative tax-financed government spending decreases relative consumption ( $\operatorname{since} \theta>2 \alpha-3$ ), although the decrease is smaller as home bias increases and more of the government spending stays in the domestic economy. Equation (T7b.2) shows that a balanced-budget increase in relative government spending increases relative output if $\alpha>1$, and, as in Mankiw (1988) and Startz (1989), the impact increases as producers' market power increases (i.e., as $\theta$ decreases). In conjunction with equation 
(T7b.1), it also shows that an increase in relative government spending - and lump-sum taxes decreases relative consumption and increases relative output as Home individuals work more. A permanent decrease in relative productivity decreases long-run relative output: as the marginal disutility of effort increases, individuals work less and output falls. From equation (T7b.3), an increase in Home relative consumption, caused perhaps by a wealth transfer, enables Home individuals to work less and increases the long-run relative price of Home products (the terms of trade). Relative government spending affects the long-run terms of trade only if there is home bias: when preferences are identical government spending falls equally on all goods in the world and therefore has no effect on relative prices.

Table 7c presents reduced forms for world consumption and world output. Since money supplies do not appear in equations (T7c.1) and (T7c.2), money is world neutral in the long run. That is, in the long run an increase in world money supply does not affect world output or consumption, although as we will we see in the next section, it does have distributional effects. The crowding out of private spending is also apparent in Table 7c: a one unit permanent increase in world government spending lowers long-run world consumption by one-half unit as the private sectors foot the tax bill (T7c.1). There is not complete crowding out because the unit increase in public spending induces a one-half unit increase in long-run world output (T7c.2). A permanent negative world productivity shock lowers world output (T7c.2) and hence world consumption (T7c.1).

Table 7c: Long-Run Reduced Forms - World Weighted Averages

$$
\begin{aligned}
& \tilde{C}^{W}=-\frac{d \bar{G}^{W}}{2 \bar{y}_{0}}-\frac{\tilde{\kappa}^{W}}{2} \\
& \tilde{y}^{W}=\frac{d \bar{G}^{W}}{2 \bar{y}_{0}}-\frac{\tilde{\kappa}^{W}}{2}
\end{aligned}
$$

Table 8 contains the equations for the MM and GG curves, which show the relationship between short-run changes in the nominal exchange rate and relative consumption. The MM curve, which is obtained using equations (T5b.6) and (T6b.4), shows how relative consumption changes, through their effect on relative money demand, affect the exchange rate. The GG curve, equation (T8.2), obtained using equations (T6b.2), (T6b.3), and (T7b.1), shows the currency depreciation - and therefore the increase in relative output - needed to justify an increase in relative consumption.

Note that in order to incorporate long-run changes of the real exchange rate into the curves -- as opposed to having a real exchange rate term -- equations (T5b.5) and (T7b.3) are also used in the derivations. Thus, even government spending and productivity shocks will shift the MM curve because of long-run real exchange rate movements, which are minuscule. When $\alpha=1$ and the real exchange rate is constant, the coefficients on the government spending and productivity terms in (T8.1) equal zero. Definitions for the $\gamma_{\mathrm{i}}$ in Table 8 are in Appendix D.

From equations (T8.1) and (T8.2) it can be shown that as $\alpha$ or $\epsilon$ increases, or $\theta$ decreases, the MM curve becomes steeper and shifts more for a given shock. Also, the GG curve flattens and shifts less for a given shock as $\alpha$ or $\theta$ increases. 
Table 8: MM and GG Curves

(MM)

$$
\begin{aligned}
\hat{E} & =-\frac{\gamma_{0}(1+\bar{r} \varepsilon)+\alpha \gamma_{2}}{\gamma_{0} \gamma_{1}+\alpha(1-\alpha) \gamma_{2}}\left(\hat{C}-\hat{C}^{*}\right)+\frac{\gamma_{0}(1+\bar{r} \varepsilon) \varepsilon}{\gamma_{0} \gamma_{1}+\alpha(1-\alpha) \gamma_{2}}\left(\tilde{M}-\tilde{M}^{*}\right) \\
& +\frac{\gamma_{2}(1-\alpha)}{\gamma_{0} \gamma_{1}+\alpha(1-\alpha) \gamma_{2}} \frac{d \bar{G}-d \bar{G}^{*}}{\bar{y}_{0}}-\frac{\gamma_{2}}{\gamma_{0} \gamma_{1}+\alpha(1-\alpha) \gamma_{2}}\left(\tilde{\kappa}-\tilde{\kappa}^{*}\right) \\
\hat{E} & =\frac{\gamma_{0}\left(\gamma_{3}+\gamma_{5}\right)-\alpha \gamma_{4}}{\alpha(1-\alpha) \gamma_{4}+\gamma_{0} \gamma_{6}}\left(\hat{C}-\hat{C}^{*}\right)+\frac{\gamma_{0}\left(\gamma_{5}+\theta-2 \alpha+3\right)-\gamma_{4}(\alpha-1)}{\alpha(1-\alpha) \gamma_{4}+\gamma_{0} \gamma_{6}}\left(\frac{d \bar{G}-d \bar{G}^{*}}{\bar{y}_{0}}\right) \\
& +\frac{\gamma_{0}(\theta-1)-\gamma_{4}}{\alpha(1-\alpha) \gamma_{4}+\gamma_{0} \gamma_{6}}\left(\tilde{\kappa}-\tilde{\kappa}^{*}\right)
\end{aligned}
$$

The solution method is to solve first for cross-country differences and world weighted averages. It is then trivial to solve for country levels. To solve for cross-country differences, use the MM and GG curves to get solutions for $\hat{E}$ and $\hat{C}-\hat{C}^{*}$, which can then be used in equation (T6b.2) to get $\hat{y}-\hat{y}^{*}$ and in equation (T6b.3) to get $d \bar{B} / \bar{y}_{0}$. Armed with $d \bar{B} / \bar{y}_{0}$, Table $7 \mathrm{~b}$ yields long-run solutions. World weighted averages are much easier to solve for; use Tables $5 \mathrm{c}, 6 \mathrm{c}$, and $7 \mathrm{c}$.

\section{III.B. A Permanent Increase in Home Relative Money Supply}

Table 9 provides world weighted averages for a permanent change in world money supply. Long-run world neutrality of money holds: in the long-run, world money supply determines world price levels (T9.2) but does not affect world output or consumption (T9.1).

Note the effect the interest elasticity of money demand, which is approximately $1 / \epsilon$, has on the shortrun effects of a permanent increase in world money supply. As $\epsilon$ increases, or money demand becomes more interest inelastic, world real interest rates (T9.4) fall more -- and, hence, world private demand and world output (T9.3) increase more -- for a given increase in world money supply.

Table 9: Money Supply Shock: World Weighted Averages

$$
\begin{aligned}
& \tilde{y}^{W}=\tilde{C}^{W}=0 \\
& \tilde{P}^{W}=\tilde{M}^{W} \\
& \hat{y}^{W}=\hat{C}^{W}=\frac{1+\bar{r} \varepsilon}{1+\bar{r}} \tilde{M}^{W} \\
& \hat{r}^{W}=-\frac{1+\bar{r} \varepsilon}{\bar{r} \beta(1+\bar{r})} \tilde{M}^{W}
\end{aligned}
$$


The short-run effects of permanent increase in relative money supply $\left(\hat{M}-\hat{M}^{*}=\tilde{M}-\tilde{M}^{*}>0\right)$ on the nominal exchange rate and relative consumption are shown graphically in Figure 2 . The initial equilibrium is at the origin: absent a policy shock the exchange rate and consumption differential are constant. From equation (T8.1), the vertical intercept of the MM curve is the amount of the permanent increase in the relative money supply, $\tilde{M}-\tilde{M}^{*}$, if preferences are identical, and is greater than $\tilde{M}-\tilde{M}^{*}$ when there is home bias: in this model nominal exchange rate changes can exceed changes in relative money supplies only if home bias exists.

Solutions for cross-country differences in the case of a permanent increase in relative money supply are given in Appendix A, equations (A.1) - (A.10). When preferences are identical the money supply shock depreciates the Home currency in the short-run (A.1) as the exchange rate jumps immediately to its long-run level (A.2), which in this case is also the PPP-level. With sticky product prices the depreciation translates directly into a fall in the relative price of Home goods, thus demand shifts towards Home goods and Home relative output increases (A.7). With the increase in the relative money supply, Home relative consumption increases as well (A.4). Home residents save part of the increase in relative real income by running a current-account surplus (A.6) to smooth consumption. ${ }^{15}$

The increased wealth from the current account surplus plays an important role in the long run. In the case of a pure monetary shock, long-run output differentials are, from equations (T7b.1) and (T7b.2), equal in magnitude to the wealth transfer. Wealthier Home residents are able to work less (A.8) while maintaining their permanent level of consumption. The long-run fall in Home relative output and increase in Home relative consumption results in a relative increase in the Home product price; that is, Home's terms of trade improves permanently. With identical tastes, Home and Foreign real interest rates fall by an identical amount: if $\alpha=1$, the real exchange rate is constant and, from equation (T6b.5), $\hat{r}=\hat{r}^{*}$.

Solutions for individual country variables are given in Appendix A, equations (A.11) - (A.17). Solutions consist of two components: the effect of changes in world money supply and the effect of changes in relative money supply. Due to the long-run world neutrality of money, the first effect is absent for long-run real variables. In the case of a permanent Home monetary expansion, the two effects work in the same direction for Home variables and in opposite directions for Foreign variables.

Consumer prices depend on exchange rate movements in the short run -- when product prices are fixed -- and both exchange rate changes and changes in product prices in the long run. Since a permanent increase in Home money supply depreciates its currency, Home CPI increases in both the short (A.11) and long (A.12) runs. Foreign CPI falls in the short run (A.11), and rises very slightly in the long run $\left(\mathrm{A} \cdot 12^{*}\right)$. Recall from (T9.2) that the long-run increase in world CPI equals the long-

15 For a pure money shock, the short-run increase in relative domestic real income is given by:

$$
\hat{y}-\hat{y}^{*}-(2-\alpha) \hat{E}=(2-\alpha)(\alpha \theta-1) \hat{E}+(\alpha-1)\left(\hat{C}-\hat{C}^{*}\right)
$$

Since demand is elastic $(\theta>1)$, if $\alpha \geq 1$ a decrease in relative price results in an increase in relative revenue. 
run increase in world money supply. Hence, for foreign CPI to fall in the long run, Home CPI would have to rise by more than the increase in money supply, which is not the case.

Real interest rates fall in the short-run in Home (A.17), and less so in Foreign (A.17*). The drop in real interest rates allows short-run consumption to increase in both countries (A.15 and A.15*), more so in Home. Due to the wealth transfer associated with Home's current account surplus, Home residents are able to maintain an increased level of consumption in the long run, whereas long-run Foreign consumption decreases (A.16), even though Foreign residents work harder (A.14). In the short run, Home output increases substantially, and Foreign output falls, due to the expenditureswitching effects of the Home exchange rate depreciation.

Figure 3 shows the effect on all of the variables of a one-percent permanent Home monetary expansion for different degrees of home bias. In each graph in Figure 3, the scale on the $\mathrm{x}$-axis is 0.01 times $\alpha$; that is, $\alpha=1$ is at the tick mark labeled ' 100 ' and $\alpha$ varies from 0.01 to 1.99 along the entire $x$-axis. Units for $y$-axes are percent changes in the indicated variables. Parameters other than $\alpha$ are fixed at levels taken from the literature $(\theta=6, \epsilon=9$, and $\beta=0.95)$; see Sutherland (1996).

It is apparent from Figure 3 that when preferences are identical $(\alpha=1)$, the exchange rate jumps immediately to its long-run level -- which corresponds to the PPP level only in this special case -and the real exchange rate is constant in both the short and long runs. The short-run nominal exchange rate overshoots its long-run level -- which no longer corresponds to the PPP level -- if $\alpha>1$, and the amount of overshooting increases with the degree of home bias. Short-run deviations from PPP become quite large as $\alpha$ increases, and long-run deviations, although of a much smaller magnitude, also increase with $\alpha$.

Figure 3 also shows the relationship between Home's current account surplus and its long-run increase in consumption. Money is not neutral in the long run in this model because a current account surplus is associated with a wealth transfer that enables residents to enjoy a long-run increase in consumption, even as long-run output falls. The current account surplus and increase in long-run consumption and short-run output all peak at about $\alpha=1.2$ : as the countries become more insular the expenditure-switching effect of the exchange rate depreciation loses its power.

\section{A Note on Exchange Rate Overshooting}

If either $\alpha$ or $\epsilon$ equals one, the short-run nominal exchange rate does not overshoot its long-run level. This was shown for $\alpha=1$ in Figure 3, but can also be shown analytically. As noted, if preferences are identical $(\alpha=1)$, the real exchange rate is constant and from equation (T5b.5) consumption differentials are permanent. In that case the short-run change in the nominal exchange rate, given by equation (T8.1), is identical to the long-run change, equation (T5b.6), as the following two equations show.

$$
\begin{array}{lr}
\hat{E}=-\frac{\hat{C}-\hat{C}^{*}}{\varepsilon}+\left(\tilde{M}-\tilde{M}^{*}\right) & \text { (if } \alpha=1) \\
\tilde{E}=-\frac{\tilde{C}-\tilde{C}^{*}}{\varepsilon}+\left(\tilde{M}-\tilde{M}^{*}\right) & \text { (if } \alpha=1)
\end{array}
$$


Logarithmic preferences for real balances, which are assumed by Ghironi (1998) and Corsetti and Pesenti (1998), also precludes exchange rate overshooting. This can be seen by subtracting (A.2) from (A.1) and setting $\epsilon=1$ :

$$
\begin{aligned}
\hat{E}-\tilde{E} & =\frac{\varepsilon\left(\tilde{M}-\tilde{M}^{*}\right)}{\gamma_{8} \gamma_{11}}\left(\gamma_{9} \gamma_{10}+\bar{r} \gamma_{8}\left(\gamma_{7} \gamma_{10}+\alpha \gamma_{2} \gamma_{8}\right)-\gamma_{9} \gamma_{10}(1+\bar{r} \varepsilon(2-\alpha))\right) \\
& =\frac{\varepsilon\left(\tilde{M}-\tilde{M}^{*}\right)}{\gamma_{8} \gamma_{11}}\left((1+\bar{r}) \gamma_{0} \gamma_{8} \gamma_{10}(1+\bar{r}(2-\alpha))-(1+\bar{r}) \gamma_{0} \gamma_{8} \gamma_{10}(1+\bar{r}(2-\alpha))\right)=0 \text {, if } \varepsilon=1
\end{aligned}
$$

where the second equality holds if $\epsilon=1$. Logarithmic preferences for real balances, while greatly simplifying solutions, come at the cost of exchange rate overshooting.

Empirical work also suggests $\epsilon=1$ should not be imposed. Recall from Section II.A that $1 / \epsilon$ is the elasticity of substitution between consumption and real balances, which can also be interpreted as the interest elasticity of real balances. In a calibration exercise, Hairault and Portier (1993) $\epsilon=9$, citing the panel data estimations of Koenig (1990), who uses post-WWII U.S. data. Thus, $\epsilon>1$ seems to be the empirically relevant case, a view also put forth by Obstfeld and Rogoff (1995, pg 645).

\section{Welfare Effects of Monetary Policy}

The effect of expansionary monetary policy on utility differs among two-country optimizing-agent models. A rather surprising result from OR is that expansionary monetary policy increases utility by the same amount in both countries, independent of which country actually inflates. However, a key result in Corsetti and Pesenti (1998), henceforth CP, is that the source of expansionary monetary policy does indeed matter: in their model expansionary Home monetary policy increases Foreign welfare and has an ambiguous effect on Home welfare.

The results of the two papers are somewhat difficult to compare, as the models differ in important ways: due to differences in utility functions and consumption indices, monetary policy is neutral in the long run in $\mathrm{CP}$, but not in OR. As discussed above, the key to the non-neutrality of money is current account transfers and their concomitant international redistribution of wealth. In the $\mathrm{CP}$ model, due to a Cobb-Douglas consumption index (and, hence, perfectly competitive goods markets) and the assumption of identical preferences, real income is constant and thus there is no incentive to lend or borrow. Without current account transfers, monetary policy shocks do not affect long-run utility. In contrast, current account imbalances play a prominent role in an OR-type model and, with identical preferences, cross-country differences in long-run utility offset differences in short-run utility.

Is it necessarily the case that allowing for current account imbalances neutralizes the cross-country utility effects of monetary policy? Not at all. OR suggest in a footnote that relaxing the assumption of zero international debt in the initial steady state would make possible differential international utility effects: a monetary expansion would result in increased utility in the debtor country and 
decreased utility for the creditor. ${ }^{16}$ Unfortunately, allowing for non-zero initial international debt means giving up closed-form solutions. I show below, though, that with idiosyncratic tastes the origin of the monetary expansion matters for relative utility, and closed-form solutions do not have to be sacrificed.

When home bias exists, monetary policy has differential utility effects. To see this, we can use the utility functions, equation (T1.1) and its foreign counterpart, to get an expression for the crosscountry change in utility due to changes in consumption and output (disregarding liquidity effects), and decompose it into short-run ( $t$ subscripts) and long-run (overbars) effects:

$$
\begin{aligned}
d U-d U^{*}= & \left(d U_{t}-d U_{t}^{*}\right)+\left(d \bar{U}-d \bar{U}^{*}\right) \\
& d U_{t}-d U_{t}^{*}=\left(\hat{C}-\hat{C}^{*}\right)-\kappa y_{0}^{2}\left(\hat{y}-\hat{y}^{*}\right)<0, \quad \alpha \geq 1 \\
& d \bar{U}-d \bar{U}^{*}=\frac{\tilde{C}-\tilde{C}^{*}}{\bar{r}}-\frac{\kappa y_{0}^{2}}{\bar{r}}\left(\tilde{y}-\tilde{y}^{*}\right)>0, \quad \alpha \geq 1
\end{aligned}
$$

For any value of $\alpha \geq 1$, a permanent relative Home monetary expansion increases relative Foreign utility in the short run (due mainly to the sharp decrease in Foreign relative effort) and relative Home utility in the long run. This is qualitatively similar to the result in CP: in the short run a relative Home monetary expansion increases relative Foreign utility. With the long-run neutrality of CP's model, the short-run utility effect is also the overall effect, and thus the story ends.

Figure 4(a) shows that OR's result that monetary policy does not affect relative utility holds only when $\alpha=1$. In Figure 4 each unit on the $x$-axes is 0.01 times $\alpha$, the $y$-axis shows changes in utility, and parameter values are as in Figure 3. When preferences are identical, the short-run and long-run effects of expansionary Home monetary policy on relative utility are equivalent: Home relative utility plummets in the short run due to the sharp increase in Home effort, but recovers in the long run as effort drops and consumption increases. If $\alpha>1$, the increase in long-run relative utility is greater than the short-run decrease, and overall Home relative utility increases. As long as there is some degree of home bias, the discounted sum of the changes in Home relative utility is positive following a permanent Home monetary expansion.

Figure 4(b) shows that as long as Home residents do not have an overwhelming preference for Foreign goods (a Foreign bias), a Home monetary expansion causes Home utility to increase. When there is a high degree of home bias, expansionary monetary policy causes utility to fall abroad.

The above discussion gives new insight into the welfare effects of monetary policy. In this framework in which utility is gained from consumption but reduced with effort (i.e., output), monetary policy is only 'beggar-thy-neighbor' in terms of utility if individuals have a preference for domestically produced goods. With identical preferences, expansionary Home monetary policy helps individuals in all countries equally. If individuals have strong preferences for imported goods, monetary policy can be immiserizing.

\footnotetext{
${ }^{16}$ See Obstfeld and Rogoff (1995), page 648.
} 


\section{III.C. A Permanent Tax-Financed Increase in Home Relative Government Spending}

Table 10 provides world weighted averages for government spending shocks. In the long run, a permanent increase in world government spending results in an increase in world output, a decrease in world private consumption (T10.1), and an increase in world CPI (T10.2). In the short run, world real interest rates (T10.5) fall more, world output (T10.4) increases more, and world consumption (T10.3) falls less, the lower is $\epsilon$. If $\epsilon=1$, world real interest rates drop enough to keep short-run world consumption from falling. In the more general and empirically relevant case of $\epsilon>1$, real interest rates fall less, and private spending is crowded out. Fiscal expansion causes a drop in real interest rates because, in this intertemporal model without investment, the real interest rate is determined by the path of output available for private consumption; with sticky prices and demand determined output in the short run, output rises more in the short run than in the long run.

Table 10: Government Spending Shock: World Weighted Averages

$$
\begin{aligned}
\tilde{C}^{W} & =-\frac{d \bar{G}^{W}}{2 \bar{y}_{0}}=-\tilde{y}^{W} \\
\tilde{P}^{W} & =\tilde{p}^{W}=\frac{d \bar{G}^{W}}{2 \varepsilon \bar{y}_{0}} \\
\hat{C}^{W} & =\left(\frac{1-\varepsilon}{2 \varepsilon(1+\bar{r})}\right) \frac{d \bar{G}^{W}}{\bar{y}_{0}} \\
\hat{y}^{W} & =\left(\frac{1+\varepsilon(1+2 \bar{r})}{2 \varepsilon(1+\bar{r})}\right) \frac{d \bar{G}^{W}}{\bar{y}_{0}} \\
\hat{r}^{W} & =-\left(\frac{1+\bar{r} \varepsilon}{2 \varepsilon(1+\bar{r})(1-\beta)}\right) \frac{d \bar{G}^{W}}{\bar{y}_{0}}
\end{aligned}
$$

Solutions for the cross-country effects of a permanent tax-financed increase in Home government spending are given in Appendix B, equations (B.1) - (B.10). The short-run effects on the nominal exchange rate and consumption differentials can be seen in Figure 5, which graphs the MM and GG schedules, given by equations (T8.1) and (T8.2) with monetary and productivity shocks set to zero. As noted, as $\alpha$ increases the negatively-sloped MM curve steepens and the positively-sloped GG curve flattens and, for a given fiscal shock, shifts less. The result is a larger exchange rate depreciation and smaller decrease in Home relative consumption; compare points A (for $\alpha>1$ ) and B (for $\alpha=1)$ in Figure 5 .

That a fiscal expansion leads to an exchange rate depreciation is somewhat non-standard. Recall, however, money demand is consumption-based. Since the expansion is tax-financed, consumption and money demand fall. With constant money supply, if money demand falls the exchange rate depreciates.

Foreign producer/consumers are affected by the Home fiscal expansion, although the spillovers are smaller as home bias increases and more spending remains in the domestic economy. The increase in public spending and the exchange rate depreciation assures that relative Home output rises in both 
the short (B.7) and long runs (B.8) by an amount that increases as more spending stays in the domestic economy (as $\alpha$ increases).

The bias parameter, $\alpha$, plays an important role in determining the sign of the short-run current account balance (B.6). When $\alpha=1$, Home runs a current account surplus only if $\theta+1>\epsilon$, which is borderline for parameter values taken from the literature. As $\alpha$ increases, however, it becomes increasingly likely that Home will run a current account surplus: only a small portion of the increased spending goes abroad, and this may be outweighed by the expenditure-switching effects of the exchange rate depreciation. ${ }^{17}$ This suggests that if U.S. trade negotiators want Japan to reduce its bilateral trade surplus, the best course would be to get Japanese residents to lower their home bias: with high home bias a Japanese fiscal expansion could well exacerbate their surplus.

Real interest rates fall after a Home fiscal expansion. As with monetary shocks, the decrease is identical in Home and Foreign if preferences are identical. As $\alpha$ increases, Home's real interest rate falls more than Foreign's (B.9).

Solutions for individual country variables are given in Appendix B, equations (B.11) - (B.17). Solutions consist of two components: the effect of changes in world public spending and the effect of changes in relative public spending.

A permanent increase in Home money supply depreciates its currency, so Home CPI increases -- and Foreign CPI falls -- in both the short (B.11) and long (B.12) runs. Home real interest rates (B.17), and to lesser extent Foreign's (B.17 ${ }^{*}$, fall in the short-run. The drop in real interest rates is not enough, however, to keep Home consumption from falling in both the short (B.15) and long (B.16) runs, as Home consumers face higher taxes. ${ }^{18}$ Lower real rates are enough to allow Foreign consumption to increase in the short run $\left(\mathrm{B} .15^{*}\right)$, but the long-run effect on Foreign consumption (B.16*) is ambiguous due to the ambiguity of the sign of the current account balance, as discussed above. If Foreign runs a current account surplus, it is more likely to be able to increase consumption in the long run.

Home output increases in the both the short (B.13) and long (B.14) runs, due to increased public demand and the expenditure-switching effects of the Home exchange rate depreciation. Home government spending has little effect on long-run Foreign output (B.14*), but the short-run effect (B.13*) is ambiguous. If home bias is severe enough, Foreign producers do not see much of the increased Home public spending and the exchange rate movements are enough to cause a drop in short-run Foreign output. If Home government spending falls more evenly on Home and Foreign products, Foreign output may well increase in the short run.

Figure 6 shows the effect on all of the variables of a permanent Home fiscal expansion for different degrees of home bias. The axes and parameter values are as in Figure 3. The exchange rate behavior apparent from Figure 3 also appears in Figure 6. When preferences are identical $(\alpha=1)$, the exchange

17 In a similar model, Sutherland (1996) uses $\varepsilon=9$ and $\theta=6$ for simulations. If $\alpha=1.6$, a fiscal expansion results in a current account surplus if $\theta+7>\varepsilon$.

18 Note that $\gamma_{15}$ in equations (B.15) and (B.16) is negative. 
rate to jumps immediately to its long-run level and the real exchange rate is constant in both the short and long runs. The short-run nominal exchange rate overshoots its long-run level if $\alpha \neq 1$, and the amount of overshooting increases the greater the home (or foreign) bias. Short-run and long-run deviations from PPP increase with $\alpha$.

Figure 6 also shows the effect of home bias on the sign of the current account balance, as discussed above: as the degree of home bias increases, a Home fiscal expansion can result in a current account surplus.

\section{III.D. A Permanent Home Negative Productivity Shock}

For an asymmetric negative productivity shock - an increase in $\kappa$, the disutility of effort - the MM and GG curves are still given by equations (T8.1) and (T8.2), but with monetary and fiscal shocks set to zero. Solutions for world weighted averages, cross-country differences, and country levels are given in Table 11 and Appendix C. Briefly, a world productivity shock lowers world output and consumption in the long run (T11.1) for any parameter values, but in the short run (T11.3) only if $\epsilon>1$. World product prices and, hence, world CPIs increase in the long run (T11.2). If $\epsilon=1$, real interest rates fall enough to leave short-run world consumption and output unaffected by a world productivity shock.

Table 11: Productivity Shock - World Weighted Averages

$$
\begin{aligned}
& \tilde{C}^{W}=\tilde{y}^{W}=-\frac{\tilde{\kappa}^{W}}{2} \\
& \tilde{P}^{W}=\tilde{p}^{W}=\frac{\tilde{\kappa}^{W}}{2 \varepsilon} \\
& \hat{C}^{W}=\hat{y}^{W}=\left(\frac{1-\varepsilon}{2 \varepsilon(1+\bar{r})}\right) \tilde{\kappa}^{W} \\
& \hat{r}^{W}=-\left(\frac{1+\bar{r} \varepsilon}{2 \varepsilon(1+\bar{r}) \bar{r} \beta}\right) \tilde{\kappa}^{W}
\end{aligned}
$$

Analytical solutions for a permanent productivity shock are presented in Appendix C; Figure 7 shows the effect of varying $\alpha$. The discussion here will focus on the relationship between relative output and the real exchange rate. Stockman (1998) notes that nearly all models of exchange rates, particularly flexible price RBC models with productivity shocks and sticky price models with monetary shocks, predict that the real exchange rate between two countries is positively correlated with their relative output levels. However, there exists nearly no empirical evidence of this correlation, although Stockman is able to find a positive nonlinear relationship.

The model developed here, which in effect encompasses a sticky price RBC model with productivity shocks, gives a possible explanation of the difficulty researchers have had documenting the relationship between real exchange rates and relative output. For the policy shocks discussed in the previous two subsections, the model predicts a positive correlation - just as other models cited by Stockman - in both the short and long runs for all values of $\alpha \geq 1$. This correlation is still predicted to be positive in the long run for productivity shocks, but may not be in the short run, depending on the degree of home bias. To see this note that in the case of a pure productivity shock and $\alpha>1$, equation (T6b.2) can be written as 
$\hat{y}-\hat{y}^{*}=\frac{\alpha(2-\alpha)}{\alpha-1} \theta \hat{Q}+(\alpha-1)\left(\hat{C}-\hat{C}^{*}\right), \quad \alpha>1$

In the face of a productivity shock, Home relative consumption falls in the short run for all values of $\alpha$. The short-run real exchange rate depreciates for any $\alpha>1$ and Home relative output still increases in the short run if the expenditure switching effect of a real depreciation is strong enough to offset the drop in relative consumption. For low degrees of home bias this is the case: in a world in which the source of goods is not important, the switching effect of a real depreciation is very strong and relative output increases. However, as home bias increases, a given real depreciation has less of an effect on relative demand and relative output may well fall.

This can also be seen in Figures 7(b) and 7(g) of short-run changes in output and the real exchange rate. Home relative output increases in the short run for low degrees of home bias, below about $\alpha=1.4$, but falls for higher degrees of home bias. The short-run real exchange rate depreciates (increases) when there is home bias. It is therefore apparent from the graphs that, in the face of a productivity shock, for low degrees of home bias there is a positive short-run relationship between relative output changes and real exchange rate changes, but a negative relationship for higher degrees of home bias.

The above argument has two implications. The difficulty researchers have had finding a positive short-run correlation between the real exchange rate and relative outputs may be due to the prevalence of productivity shocks, sticky prices, and home bias. Even in this case, however, the positive correlation may well be apparent in long-run components. 


\section{Mundell-Fleming, Obstfeld-Rogoff and Idiosyncratic Preferences}

Frenkel, Razin and Yuen (1996, Chapter 3) presents a two-country MF model that allows for idiosyncratic tastes and has money demand depending on disposable, not total, income. In all other respects it is relatively standard in that it assumes perfect capital mobility, flexible exchange rates, static expectations, and sticky prices. ${ }^{19}$ Using this model we can contrast the short-run effects of policy shocks in four models: versions of OR and MF with both identical and idiosyncratic tastes.

Differentiating the goods demand and money demand equations (3.20) - (3.23) in Frenkel, Razin, and Yuen (1996), with Foreign variables denoted by asterisks, yields:

$$
\left(\begin{array}{cccc}
-(s+a) & e_{t} a^{*} & I M_{t}^{*} & H_{r} \\
a & -e_{t}\left(s^{*}+a^{*}\right) & -I M_{t} & F_{r} \\
M_{y} & 0 & 0 & M_{r} \\
0 & M_{y^{*}}^{*} & 0 & M_{r}^{*}
\end{array}\right)\left(\begin{array}{c}
d Y \\
d Y^{*} \\
d e \\
d r
\end{array}\right)=\left(\begin{array}{c}
(1-a)(d T-d G)-s d T \\
a(d T-d G) \\
d M+M_{y} d T \\
d M^{*}
\end{array}\right)
$$

where
$\mathrm{s}$, a marginal propensities to save and import
e nominal exchange rate (Home currency price of a unit of Foreign currency)
$\mathrm{G}, \mathrm{T}$ real government spending and taxes
Y real output or income
$\mathrm{r} \quad$ real (or nominal) interest rate
IM foreign value of imports (i.e., domestic exports)
$M_{y}, M_{r} \quad$ partial derivatives of money demand
$\mathrm{H}_{\mathrm{r}}, \mathrm{F}_{\mathrm{r}} \quad$ partial effect of a change in the interest rate on $\mathrm{Y}$ and $\mathrm{Y}^{*}$

Table 12 contains the comparative static results for two policy experiments - a Home monetary expansion and a balanced-budget Home fiscal expansion - using the same assumptions as in this paper: initially balanced trade, zero initial net foreign assets, and two countries that are mirror images with identical behavioral parameters.

Table 12 also shows the familiar 'beggar-thy-neighbor' effect for output of a monetary expansion in a two-country MF model. A Home monetary expansion increases Home output through two channels: a drop in the real interest rate and a nominal exchange rate depreciation. Foreign output falls, however, as the expansionary effect of a decreased real interest rate is swamped by the

19 This basic MF model is used to keep the analysis simple and because it is a part of many economists' toolkits. See McKibbin and Sachs (1991) for a more advanced version of the MF model that incorporates intertemporal dynamics, expectations, and a supply side, using extensions discussed by Branson and Henderson (1985), Dornbusch (1976), Frenkel and Razin (1988) and Bruno and Sachs (1985). 
contractionary effect of its exchange rate appreciation. ${ }^{20}$ These results are qualitatively no different than the ones obtained in the previous section.

Table 12: Two-Country Mundell-Fleming Model

Comparative Statics: Domestic Monetary Expansion $(d \mathbf{M}=1)$

$$
\begin{array}{ccc}
\frac{\partial Y}{\partial M}=\frac{M_{y}\left(F_{r}+H_{r}\right)+M_{r} e_{t} s}{\Delta}>0 ; & \frac{\partial Y^{*}}{\partial M}=\frac{-M_{r} s}{\Delta}<0 ; & \frac{\partial r}{\partial M}=\frac{M_{y} s}{\Delta}<0 ; \\
\frac{\partial e}{\partial M}=\frac{M_{y}\left(F_{r}(s+a)+a H_{r}\right)+M_{r} e_{t} s(2 a+s)}{\left(I M_{t}\right) \Delta}>0 ; & \Delta=M_{y}\left(M_{y}\left(F_{r}+H_{r}\right)+M_{r} s\left(1+e_{t}\right)\right)
\end{array}
$$

Comparative Statics: Domestic Balanced Budget Fiscal Expansion $(d \mathrm{G}=d \mathrm{~T}=1)$

$$
\frac{\partial Y}{\partial G}=1 ; \quad \frac{\partial Y^{*}}{\partial G}=0 ; \quad \frac{\partial e}{\partial G}=\frac{a}{I M_{t}} ; \quad \frac{\partial r}{\partial G}=0
$$

Less familiar results are also apparent in Table 12. The effects of a balanced-budget Home fiscal expansion in this version of a two-country MF model depend crucially on disposable, not total, income entering the money demand functions. Home output and, by assumption, taxes increase onefor-one with the increase in government spending, so disposable income is unchanged. Since money demand depends on disposable income, it too is unchanged and the real interest rate remains constant; thus Foreign output is unaffected. ${ }^{21}$ The nominal exchange rate depreciates - contrary to the familiar result from a small-country MF model - to eliminate the excess demand for Foreign goods caused by the increase in Home government imports.

That the basic results from a relatively standard two-country MF model - which, in some version, has been used by international economists for three decades - and an optimizing-agent model are so similar should be comforting to practitioners and policymakers. The models do, however, differ in the details, in particular concerning the role of home bias. As shown in Section III, in my model the magnitudes of most variables depend on the degree of home bias. However, in the two-country MF model only the exchange rate depends on the marginal propensity to import (MPI), and, in direct contrast to my model, it exhibits greater swings the higher is the MPI. Which model makes predictions that are more consistent with observed behavior is an empirical matter. Regardless, what

20 This is readily seen in Foreign's money demand equation, the final equation in the above system. For a given Foreign money supply, the effects on Foreign money demand of income and interest rate changes must be offsetting. A drop in the real interest rate would increase money demand, so a drop in Foreign output is required to keep the Foreign money market in equilibrium.

21 If money demand depends instead on total income, a balanced-budget fiscal expansion would result in an increase in the real interest rate (as long as the marginal propensity to save is positive), and the exchange rate would adjust to allow Foreign output to increase by the same amount as Home output. 
has been shown here is important: a dynamic optimizing model with idiosyncratic tastes makes predictions that are, in a broad sense, similar to those of the workhorse model of open-economy macroeconomics.

\section{Conclusions}

The model presented in this paper is a significant step towards reconciling the optimizing framework with the policy conclusions of the two-country Mundell-Fleming model by introducing idiosyncratic tastes, or a home bias in consumption. A simple dynamic optimizing model is presented that not only broadly replicates the policy conclusions of MF, but also makes plausible predictions about exchange rate behavior. That the model is broadly consistent with MF is reassuring, but should not inspire complacency. The details, especially concerning the effects of home bias, are quite different in the two types of models.

Home bias has important implications for the effects of policy shocks. In a world with home bias, the international leakages of expansionary fiscal policy are reduced if not reversed, and a fiscal expansion could well lead to an improvement in the current account balance. Moreover, the effects of a monetary shock on relative utility depend crucially on the degree of home bias: only if individuals have a greater preference for domestic goods will a monetary expansion result in increased relative utility.

The model with idiosyncratic preferences has a number of implications for exchange rate determination. Not surprisingly, in a model with sticky prices and different consumption baskets across countries, there are short-term deviations from PPP. However, the model is also consistent with an aspect of exchange rate behavior that has been particularly puzzling to economists, the persistence of deviations from PPP. As argued in Krugman (1990), if preferences are idiosyncratic wealth transfers affect the real exchange rate. In my model any asymmetric shock results in a current account imbalance and, hence, long-run wealth transfers and persistent deviations from PPP. Also, idiosyncratic tastes result in increased the volatility of real and nominal exchange rates and greater Dornbusch (1976) type overshooting. In this light it is not surprising that for decades economists have failed to find much evidence of PPP using U.S. dollar exchange rates, as even today the U.S. economy is relatively closed.

The model is decidedly simple in a number of respects. The absence of investment and the simplicity of the supply process preclude the model from replicating observed patterns in output. Price dynamics would have to be considerably richer if one were to bring the model to the data. A comparison with bond-financed fiscal expansions in the MF model could be made if money demand were allowed to depend on total, not disposable, income, as it would if real balances were in the production function. The assumption of mirror-image countries could be relaxed if one were content with numerical solutions; the author is presently working on an $n$-country version of the model, to be solved numerically in GAUSS, in which country sizes and bias parameters are not constrained to be identical.

A natural extension of the two-country model developed here is to allow monetary policy to react endogenously to changes in the economy through a monetary policy rule or to the behavior of policy 
makers in the other country. Various monetary policy rules can be ranked according to their ability to stabilize the economy in the face of asymmetric and symmetric productivity and fiscal shocks, along the lines of Henderson and McKibbin (1993). Strategic interactions between policymakers can be analyzed, as in McKibbin and Sachs (1991) and Canzoneri and Henderson (1991); an initial attempt at this is found in Warnock (1999).

Finally, the model can be used as a basis for empirical work. Recall, the model predicts that greater home bias results in a higher correlation between real and nominal exchange rates and larger, persistent deviations from PPP. Preliminary work by the author finds somw support for the latter in a post-1973 sample of twenty industrial countries, with a measure of bilateral trade proxying for home bias. 


\section{Bibliography}

Ball, Laurence and David Romer. "Are Prices Sticky?" Quarterly Journal of Economics 104 (August 1989): 507-24.

Blanchard, Olivier and Nobuhiro Kiyotaki. "Monopolistic Competition and the Effects of Aggregate Demand." American Economic Review 77 (1987): 647-66.

Branson, William H. and Dale W. Henderson. "The Specification and Influence of Asset Markets" in Jones, Ronald W. and Peter B. Kenen, eds: Handbook of International Economics, Volume 2. Elsevier Science, B.V., 1985.

Bruno, Michael and Jeffrey Sachs, Economics of Worldwide Stagflation. Harvard University Press, 1985.

Canzoneri, Matthew and Dale Henderson. Monetary Policy in Interdependent Economies: A Game Theoretic Approach. MIT Press, 1991.

Corsetti, Giancarlo and Paolo Pesenti. "Welfare and Macroeconomic Interdependence." unpublished manuscript, Yale University and Princeton University, 1998.

Devereux, Michael. "Real Exchange Rates and Macroeconomics: Theory and Evidence." Canadian Journal of Economics 30 (1997): 773-808.

Dixit, Avinash and Joseph Stiglitz. "Monopolistic Competition and Optimum Product Diversity." American Economic Review 67 (1977): 297-308.

Dornbusch, Rudiger. "Expectations and Exchange Rate Dynamics." Journal of Political Economy 84 (1976): 1161-76.

Fleming, J. Marcus. "Domestic Financial Policies Under Fixed and Under Floating Exchange Rates." International Monetary Fund Staff Papers 9 (1962): 369-79.

Frenkel, J.A. and A. Razin. Fiscal Policies and the World Economy. $1^{\text {st }}$ ed., MIT Press, 1988.

Frenkel, J.A., A. Razin and Chi-Wa Yuen. Fiscal Policies and Growth in the World Economy. $3^{\text {rd }}$ ed., MIT Press, 1996.

Froot, Kenneth and Kenneth Rogoff. "Perspectives on PPP and Long-Run Real Exchange Rates," in The Handbook of International Economics. Vol. 3. Eds.: Gene Grossman and Kenneth Rogoff. Amsterdam, Elsevier Press, 1995. 
Ghironi, Fabio. "U.S.-Europe Economic Interdependence (I): Positive Analysis." unpublished manuscript, University of California-Berkeley, 1998.

Hagiwara, May. "Volatility in the Terms of Trade with Non-Identical Preferences." Journal of International Money and Finance 13 (1994): 319-341.

Hairault, Jean-Olivier and Frank Portier. "Money, New-Keynesian Macroeconomics and the Business Cycle." European Economic Review 37 (1993): 1533-1568.

Henderson, Dale and Warwick McKibbin. "A Comparison of Some Basic Monetary Policy Regimes for Open Economies: Implications for Different Degrees of Instrument Adjustment and Wage Persistence." Carnegie-Rochester Conference Series on Public Policy 39 (1993): 221-317.

Koenig, Evan. "Real Money Balances and the Timing of Consumption: An Empirical Investigation." Quarterly Journal of Economics 105 (1990): 399-425.

Krugman, Paul. "Equilibrium Exchange Rates," in International Monetary Policy Coordination and Exchange Rate Fluctuations. Eds.: William Branson, Jacob Frenkel and Morris Goldstein. Chicago: U. of Chicago Press, 1990, pp 159-187.

Lucas, Robert E., Jr. "Interest Rates and Currency Prices in a Two-Country World." Journal of Monetary Economics 10 (1982): 335-359.

MacDonald, Ronald. Floating Exchange Rates: Theories and Evidence. London, Unwin-Hyman, 1988.

Mankiw, N. Gregory. "Small Menu Costs and Large Business Cycles: A Macroeconomic Model of Monopoly." Quarterly Journal of Economics 100 (1985): 529-538.

. "Imperfect Competition and the Keynesian Cross." Economics Letters 26 (1988): 7-14.

McKibbin, Warwick and Jeffrey Sachs. Global Linkages: Macroeconomic Interdependence and Cooperation in the World Economy. Washington, DC: The Brookings Institution, 1991.

Mundell, Robert A. "Capital Mobility and Stabilization Policy Under Fixed and Flexible Exchange Rates." Canadian Journel of Economics 29 (1963):475-85. International Economics. New York: MacMillan, 1968.

Obstfeld, Maurice and Kenneth Rogoff. "Exchange Rate Dynamics Redux." Journal of Political Economy 103 (1995): 624-660.

. Foundations of International Macroeconomics. Cambridge, MA: MIT Press, 1996.

Startz, Richard. "Monopolistic Competition as a Foundation for Keynesian Macroeconomic Models." Quarterly Journal of Economics 104 (1989): 737-52. 
Stockman, Alan. "New Evidence Connecting Exchange Rates to Business Cycles." Economic Quarterly, Federal Reserve Bank of Richmond 84(2) Spring 1998.

Sutherland, Alan. "Exchange Rate Dynamics and Financial Market Integration." CEPR Discussion Paper 1337 (1996).

Tille, Cedric. "The International and Domestic Welfare Effects of Monetary Policy Under Pricing-toMarket." unpublished manuscript, Princeton University, 1998.

Warnock, Francis E. "Optimal Monetary Policy Coordination in a Two-Country Optimizing Model." unpublished manuscript, University of North Carolina, 1999. 


\section{Figures}

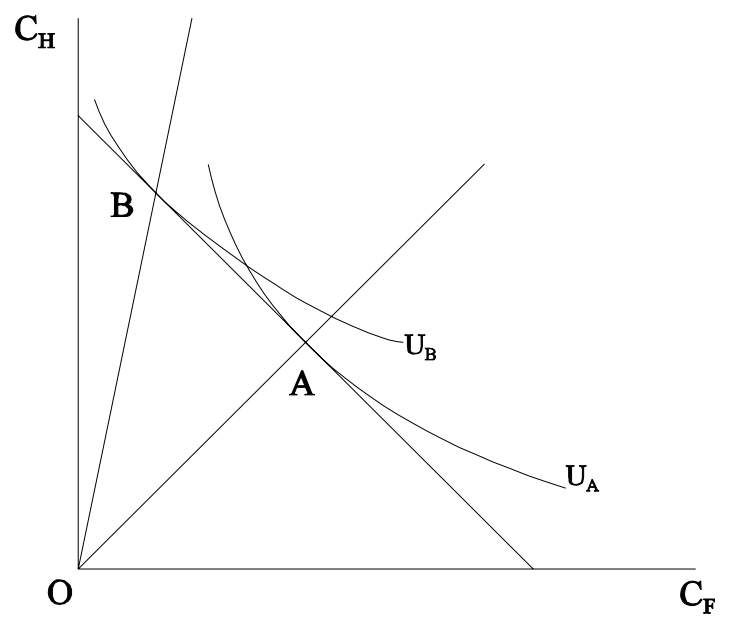

Figure 1: A Home Individual's Intratemporal Consumption Choice 
Figure 2: Short-run changes from an unanticipated permanent increase in Home money supply. Pre-shock equilibrium is at the origin. Primed, thick curves and the post-shock equilibrium A are drawn for $\alpha>1$; unprimed curves and point B are drawn for $\alpha=1$.

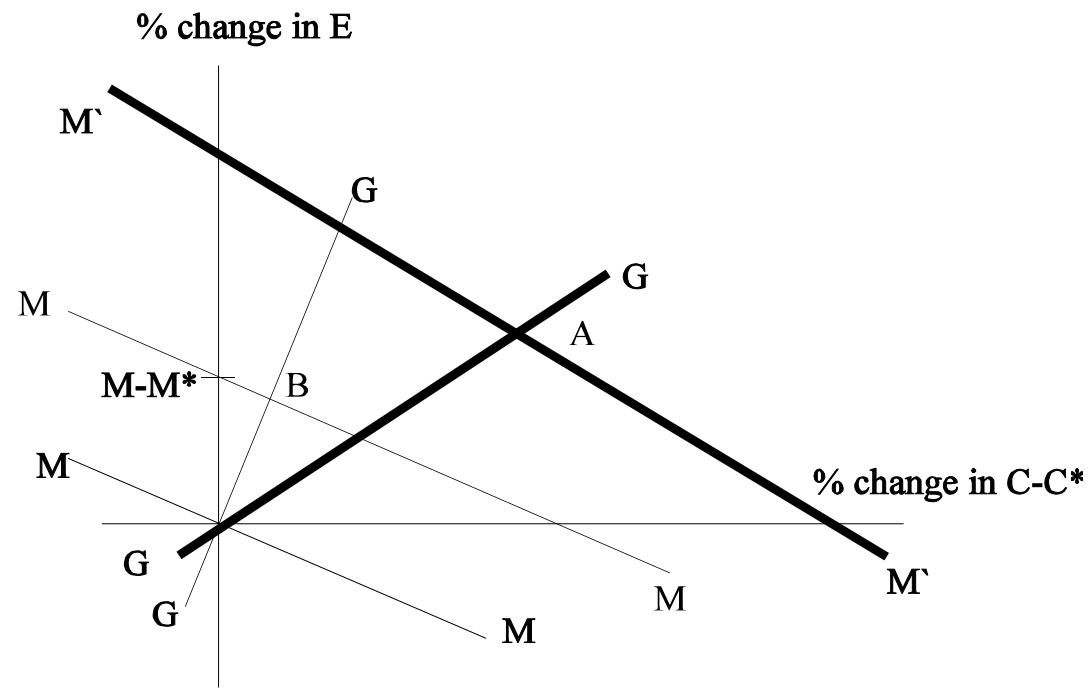



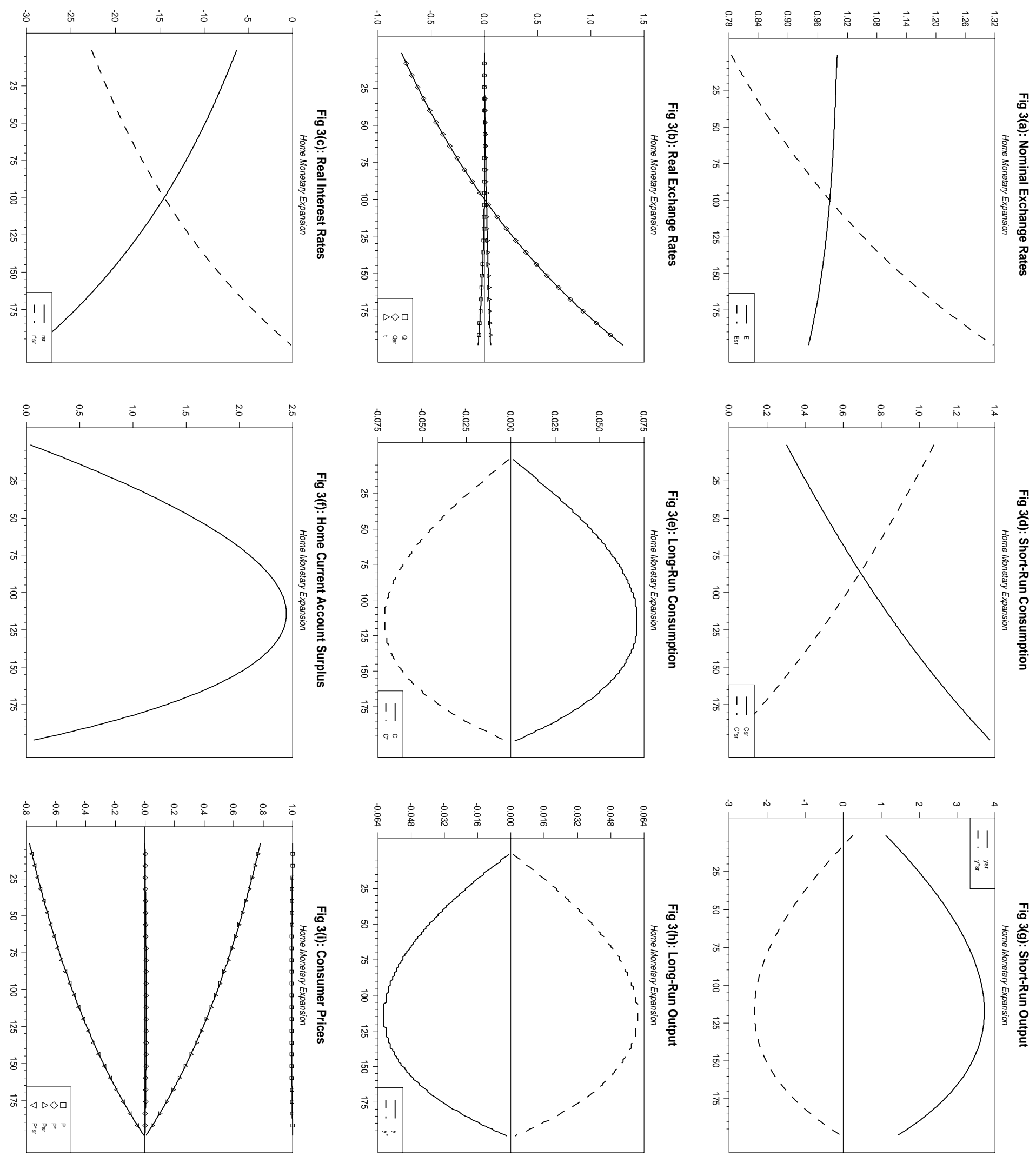

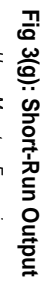


Fig 4(a): Change in Relative Utility

Infinite-Period, Short Run, and Long Run

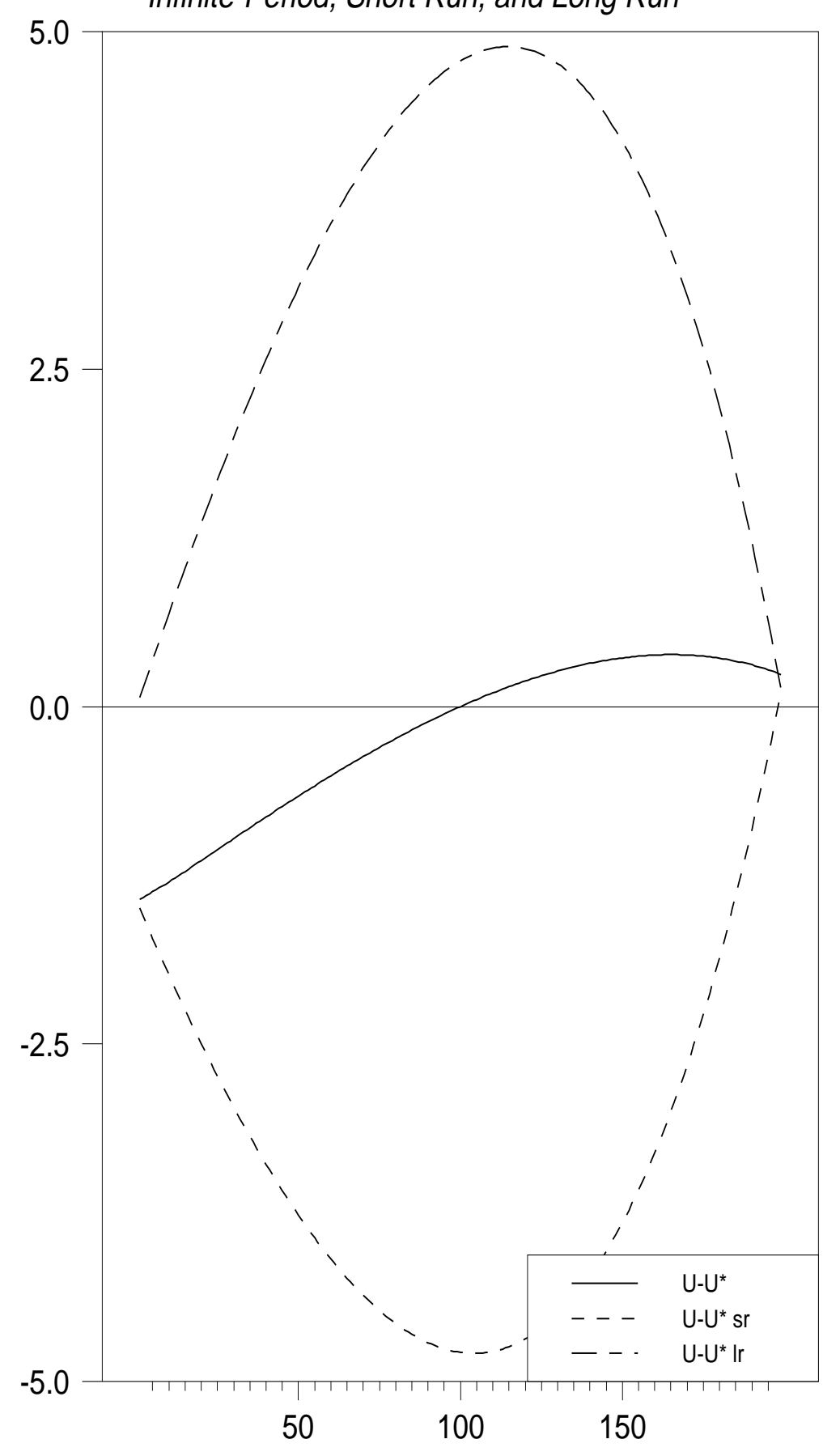

Fig 4(b): Infinite-Period Change in Utility

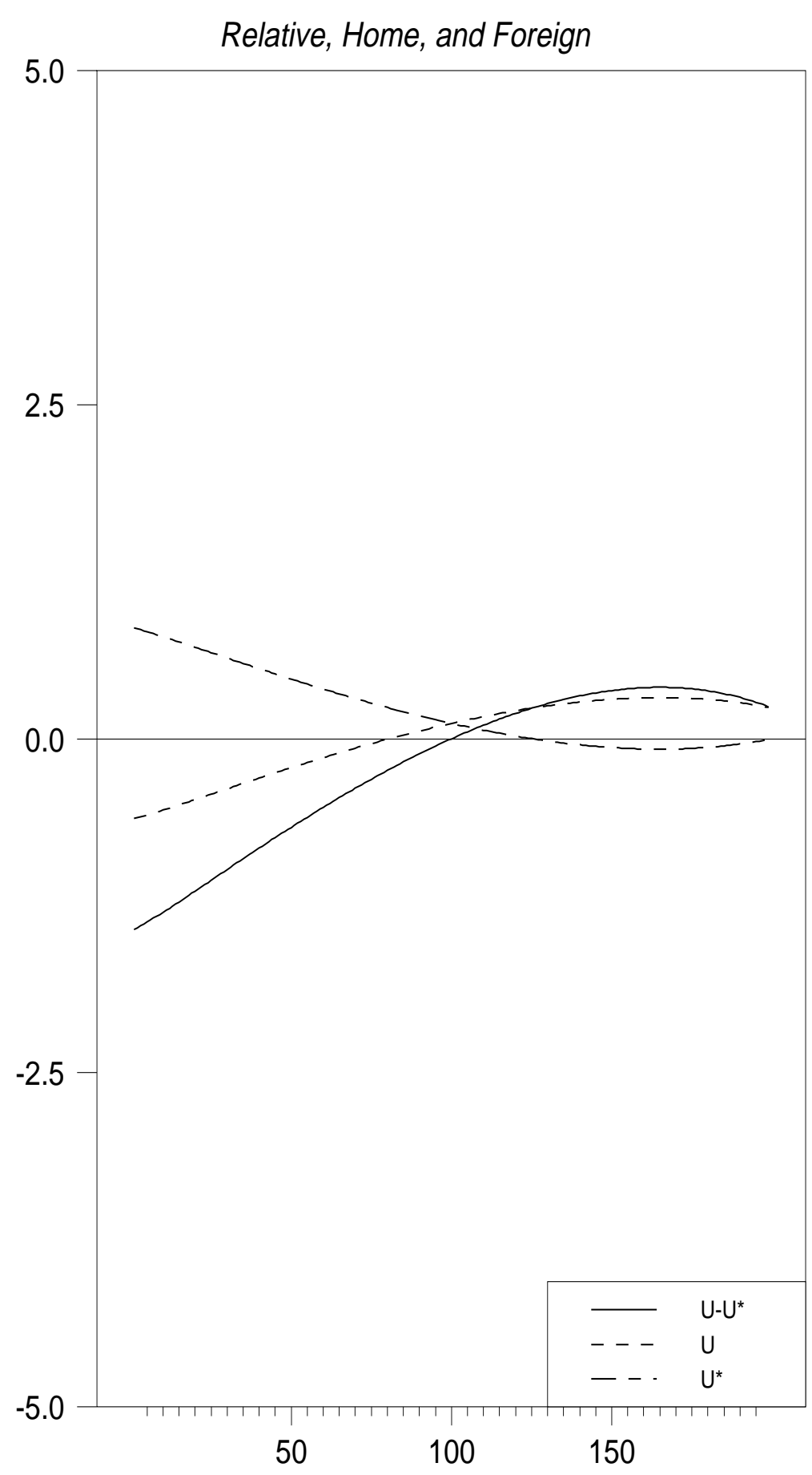


Figure 5: Short-run changes from an unanticipated permanent increase in Home government spending. Pre-shock equilibrium is at the origin. Primed, thick curves and the post-shock equilibrium $A$ are drawn for $\alpha>1$; unprimed curves and point B are drawn for $\alpha=1$.

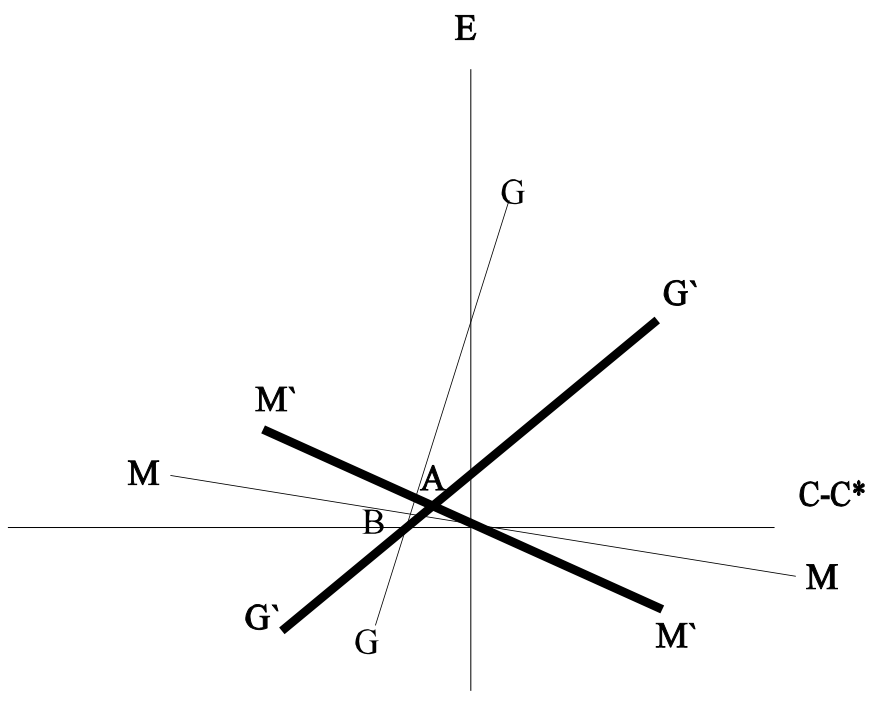



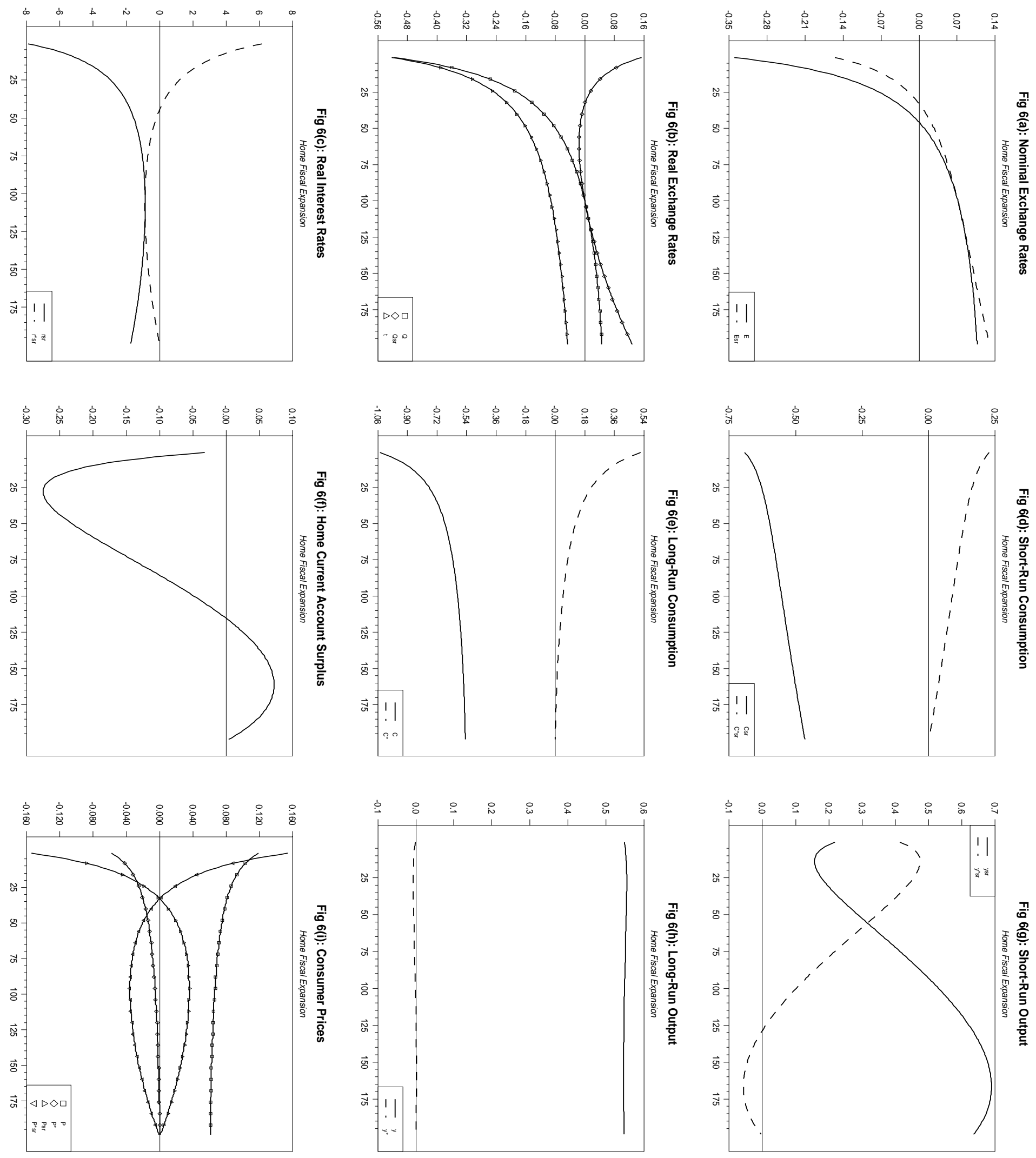

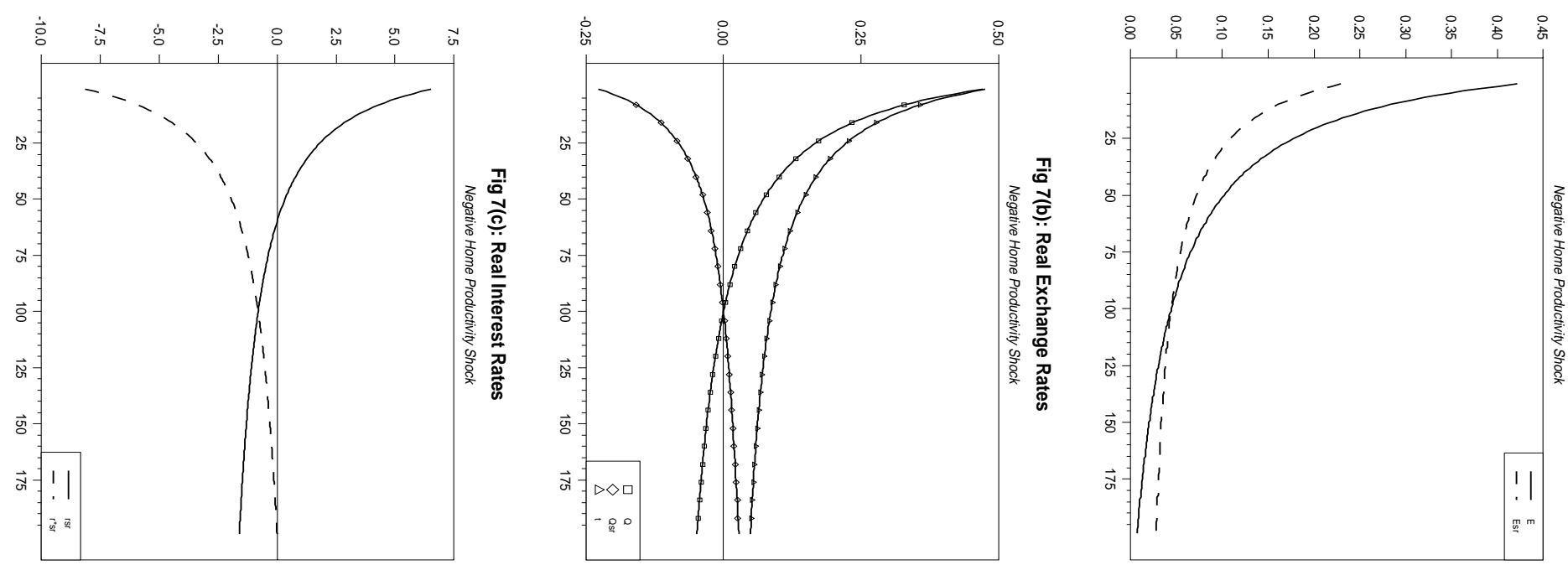

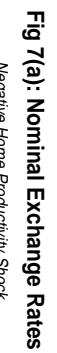
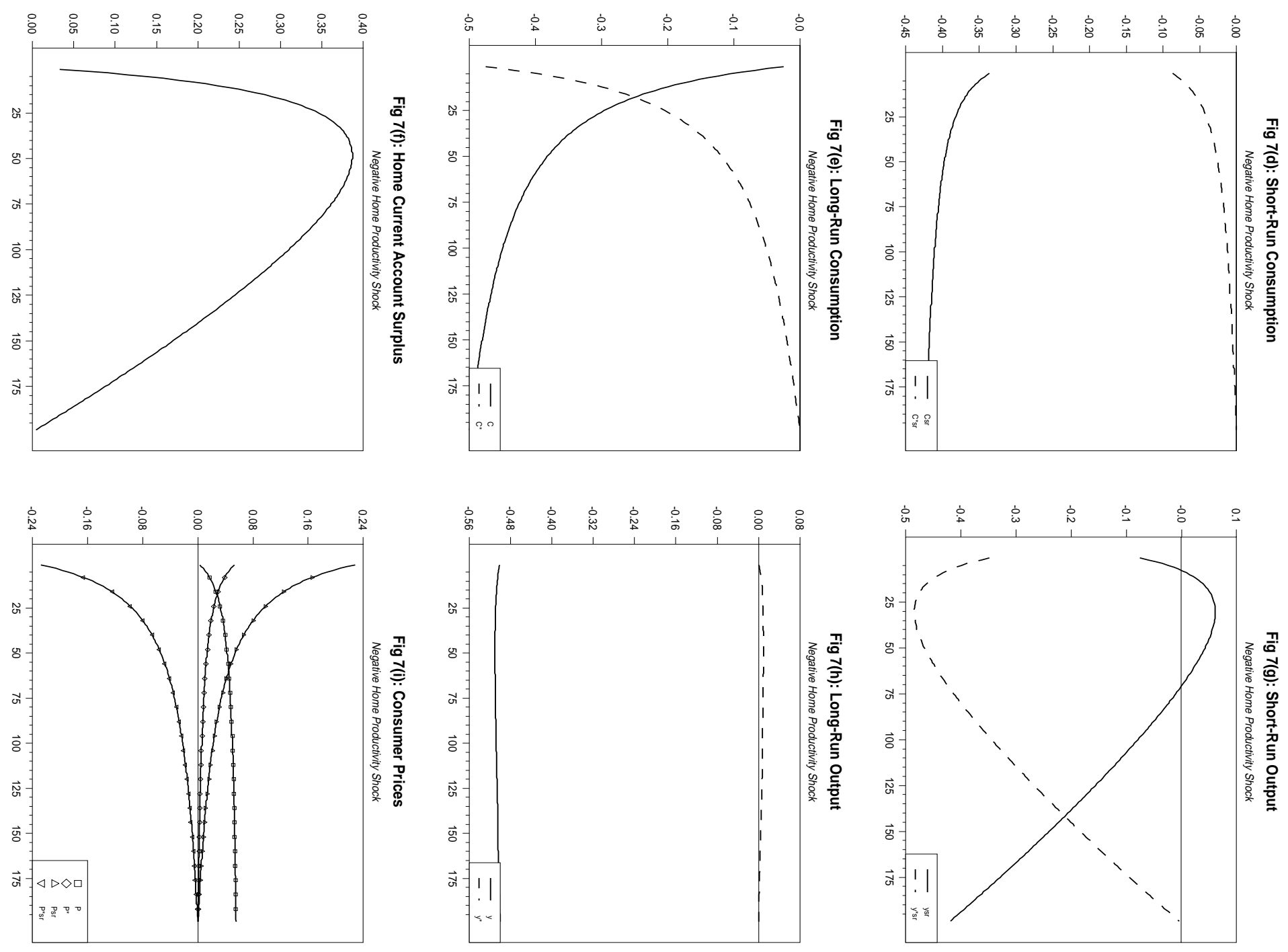


\section{Appendix: Analytical Solutions}

\section{A. Permanent Money Shock}

\section{$\underline{\text { Cross-Country Differences }}$}

$$
\left.\begin{array}{l}
\hat{E}=\left(\tilde{M}-\tilde{M}^{*}\right) \frac{\varepsilon \gamma_{9} \gamma_{10}}{\gamma_{8} \gamma_{11}} \\
\tilde{E}=\frac{\varepsilon\left(\tilde{M}-\tilde{M}^{*}\right)}{\gamma_{8} \gamma_{11}}\left((1+\bar{r} \varepsilon(2-\alpha)) \gamma_{9} \gamma_{10}-\bar{r} \gamma_{8}\left(\gamma_{7} \gamma_{10}+\alpha \gamma_{2} \gamma_{8}\right)\right) \\
\tilde{t}=\left(\tilde{M}-\tilde{M}^{*}\right) \frac{\alpha \varepsilon \gamma_{5} \gamma_{9} \gamma_{12}}{2(2-\alpha) \gamma_{8} \gamma_{11} \gamma_{13}} \\
\hat{C}-\hat{C}^{*}=\left(\tilde{M}-\tilde{M}^{*}\right) \frac{\varepsilon \gamma_{9}}{\gamma_{11}} \\
\tilde{C}-\tilde{C}^{*}=\left(\tilde{M}-\tilde{M}^{*}\right) \frac{(1+\alpha \theta) \varepsilon \gamma_{5} \gamma_{9} \gamma_{12}}{2 \gamma_{8} \gamma_{11} \gamma_{13}} \\
\frac{d \bar{B}}{\bar{y}}=\left(\tilde{M}-\tilde{M}^{*}\right) \frac{(2-\alpha) \varepsilon \gamma_{9} \gamma_{12}}{2 \gamma_{8} \gamma_{11}} \\
\hat{y}-\hat{y}^{*}=\left(\tilde{M}-\tilde{M}^{*}\right) \frac{\varepsilon \gamma_{9}\left(\alpha(2-\alpha) \theta \gamma_{10}+(\alpha-1) \gamma_{8}\right)}{\gamma_{8} \gamma_{11}} \\
\hat{r}-\hat{r}^{*}=\left(\tilde{M}-\tilde{M}^{*}\right) \frac{(1-\alpha) \varepsilon \gamma_{9}\left(\alpha \gamma_{5} \gamma_{12}+2(2-\alpha) \gamma_{10} \gamma_{13}\right)}{2(1-\beta)(2-\alpha) \gamma_{8} \gamma_{11} \gamma_{13}} \\
\tilde{y}-\tilde{y}^{*}=\left(\tilde{M}-\tilde{M}^{*}\right) \frac{-\varepsilon(1-\alpha+\alpha \theta) \gamma_{5} \gamma_{9} \gamma_{12}}{2 \gamma_{8} \gamma_{11} \gamma_{13}} \\
\left.\frac{(1+\alpha \theta) \gamma_{5} \gamma_{9} \gamma_{12}}{2 \gamma_{8} \gamma_{11} \gamma_{13}}\right)
\end{array}\right)
$$




\section{$\underline{\text { Country Levels }}$}

$$
\begin{aligned}
& \hat{P}=-\hat{P}^{*}=\left(\tilde{M}-\tilde{M}^{*}\right) \frac{(2-\alpha) \varepsilon \gamma_{9} \gamma_{10}}{2 \gamma_{8} \gamma_{11}} \\
& \tilde{P}=\tilde{M}^{W}+\left(\tilde{M}-\tilde{M}^{*}\right)\left(1 / 2-\frac{(1+\alpha \theta) \gamma_{5} \gamma_{9} \gamma_{12}}{4 \gamma_{8} \gamma_{11} \gamma_{13}}\right) \\
& \tilde{P}^{*}=\tilde{M}^{W}-\left(\tilde{M}-\tilde{M}^{*}\right)\left(1 / 2-\frac{(1+\alpha \theta) \gamma_{5} \gamma_{9} \gamma_{12}}{4 \gamma_{8} \gamma_{11} \gamma_{13}}\right) \\
& \hat{y}=\frac{1+\bar{r} \varepsilon}{(1+\bar{r})} \tilde{M}^{W}+\frac{\varepsilon \gamma_{9}\left(\alpha(2-\alpha) \theta \gamma_{10}+(\alpha-1) \gamma_{8}\right)}{2 \gamma_{8} \gamma_{11}}\left(\tilde{M}-\tilde{M}^{*}\right) \\
& \hat{y}^{*}=\frac{1+\bar{r} \varepsilon}{(1+\bar{r})} \tilde{M}^{W}-\frac{\varepsilon \gamma_{9}\left(\alpha(2-\alpha) \theta \gamma_{10}+(\alpha-1) \gamma_{8}\right)}{2 \gamma_{8} \gamma_{11}}\left(\tilde{M}-\tilde{M}^{*}\right) \\
& \tilde{y}=-\tilde{y}^{*}=\left(\tilde{M}-\tilde{M}^{*}\right) \frac{-\varepsilon(1-\alpha+\alpha \theta) \gamma_{5} \gamma_{9} \gamma_{12}}{4 \gamma_{8} \gamma_{11} \gamma_{13}} \\
& \hat{C}=\frac{1+\bar{r} \varepsilon}{(1+\bar{r})} \tilde{M}^{W}+\frac{\varepsilon \gamma_{9}}{2 \gamma_{11}}\left(\tilde{M}-\tilde{M}^{*}\right) \\
& \hat{C}^{*}=\frac{1+\bar{r} \varepsilon}{(1+\bar{r})} \tilde{M}^{W}-\frac{\varepsilon \gamma_{9}}{2 \gamma_{11}}\left(\tilde{M}-\tilde{M}^{*}\right) \\
& \tilde{C}=-\tilde{C}^{*}=\left(\tilde{M}-\tilde{M}^{*}\right) \frac{(1+\alpha \theta) \varepsilon \gamma_{5} \gamma_{9} \gamma_{12}}{4 \gamma_{8} \gamma_{11} \gamma_{13}} \\
& \hat{r}=-\frac{1+\bar{r} \varepsilon}{\bar{r} \beta(1+\bar{r})} \tilde{M}^{W}-(\alpha-1) \varepsilon \gamma_{9}\left(\frac{2(2-\alpha) \gamma_{10} \gamma_{13}+\alpha \gamma_{5} \gamma_{12}}{4(2-\alpha) \bar{r} \beta \gamma_{8} \gamma_{11} \gamma_{13}}\right)\left(\tilde{M}-\tilde{M}^{*}\right) \\
& \hat{r}^{*}=-\frac{1+\bar{r} \varepsilon}{\bar{r} \beta(1+\bar{r})} \tilde{M}^{W}+(\alpha-1) \varepsilon \gamma_{9}\left(\frac{2(2-\alpha) \gamma_{10} \gamma_{13}+\alpha \gamma_{5} \gamma_{12}}{4(2-\alpha) \bar{r} \beta \gamma_{8} \gamma_{11} \gamma_{13}}\right)\left(\tilde{M}-\tilde{M}^{*}\right)
\end{aligned}
$$




\section{B. Permanent Government Spending Shock}

\section{Cross-Country Differences}

$\hat{E}=\left(\frac{d \bar{G}-d \bar{G}^{*}}{\bar{y}_{0}}\right) \frac{\gamma_{17}}{\gamma_{8} \gamma_{11}}$

$\tilde{E}=\left(\frac{d \bar{G}-d \bar{G}^{*}}{\bar{y}_{0}}\right) \frac{(1+\bar{r} \varepsilon(2-\alpha)) \gamma_{17}+\bar{r} \gamma_{15} \gamma_{8}}{\gamma_{11}}$

$\tilde{t}=\left(\frac{d \bar{G}-d \bar{G}^{*}}{\bar{y}_{0}}\right) \frac{\gamma_{18}}{\gamma_{0} \gamma_{8} \gamma_{11}}$

$\hat{C}-\hat{C}^{*}=\left(\frac{d \bar{G}-d \bar{G}^{*}}{\bar{y}_{0}}\right) \frac{\gamma_{15}}{\gamma_{11}}$

$\tilde{C}-\tilde{C}^{*}=\left(\frac{d \bar{G}-d \bar{G}^{*}}{\bar{y}_{0}}\right)\left(\frac{\gamma_{15}}{\gamma_{11}}+\frac{(1-\alpha)\left(\gamma_{0} \gamma_{17}+\gamma_{18}\right)}{\gamma_{0} \gamma_{8} \gamma_{11}}\right)$

$\frac{d \bar{B}}{\bar{y}_{0}}=(1-\alpha / 2)\left(\frac{d \bar{G}-d \bar{G}^{*}}{\bar{y}_{0}}\right)\left(\frac{\gamma_{17}(\alpha \theta-1)-\gamma_{8}\left(\gamma_{15}+\gamma_{11}\right)}{\gamma_{8} \gamma_{11}}\right)$

$\hat{y}-\hat{y}^{*}=\left(\frac{d \bar{G}-d \bar{G}^{*}}{\bar{y}_{0}}\right) \frac{\alpha \theta(2-\alpha) \gamma_{17}+(\alpha-1) \gamma_{8}\left(\gamma_{15}+\gamma_{11}\right)}{\gamma_{8} \gamma_{11}}$

$\tilde{y}-\tilde{y}^{*}=\left(\frac{d \bar{G}-d \bar{G}^{*}}{\bar{y}_{0}}\right) \frac{(\alpha-1) \gamma_{0} \gamma_{8} \gamma_{11}-(2-\alpha)(1-\alpha+\alpha \theta) \gamma_{18}}{\alpha \gamma_{0} \gamma_{8} \gamma_{11}}$

$\hat{r}-\hat{r}^{*}=(1-\alpha)\left(\frac{d \bar{G}-d \bar{G}^{*}}{\bar{y}_{0}}\right) \frac{\gamma_{0} \gamma_{17}+\gamma_{18}}{(1-\beta) \gamma_{0} \gamma_{8} \gamma_{11}}$

$\tilde{P}-\tilde{P}^{*}=-\left(\frac{d \bar{G}-d \bar{G}^{*}}{\bar{y}_{0}}\right)\left((1-\alpha) \frac{\gamma_{0} \gamma_{17}+\gamma_{18}}{\varepsilon \gamma_{0} \gamma_{8} \gamma_{11}}+\frac{\gamma_{15}}{\varepsilon \gamma_{11}}\right)$ 


\section{$\underline{\text { Country Levels }}$}

$$
\begin{aligned}
& \hat{P}=-\hat{P}^{*}=-\left(\frac{d \bar{G}-d \bar{G}^{*}}{\bar{y}_{0}}\right) \frac{(2-\alpha) \gamma_{17}}{2 \gamma_{8} \gamma_{11}} \\
& \tilde{P}=-\tilde{P}^{*}=-\left(\frac{d \bar{G}-d \bar{G}^{*}}{2 \bar{y}_{0}}\right)\left((1-\alpha) \frac{\gamma_{0} \gamma_{17}+\gamma_{18}}{\varepsilon \gamma_{0} \gamma_{8} \gamma_{11}}+\frac{\gamma_{15}}{\varepsilon \gamma_{11}}\right)+\frac{d \bar{G}^{W}}{2 \varepsilon \bar{y}_{0}} \\
& \hat{y}=\left(\frac{d \bar{G}-d \bar{G}^{*}}{\bar{y}_{0}}\right) \frac{\alpha \theta(2-\alpha) \gamma_{17}+(\alpha-1) \gamma_{8}\left(\gamma_{15}+\gamma_{11}\right)}{2 \gamma_{8} \gamma_{11}}+\left(\frac{1+\varepsilon(1+2 \bar{r})}{2 \varepsilon(1+\bar{r})}\right) \frac{d \bar{G}^{W}}{\bar{y}_{0}} \\
& \hat{y}^{*}=-\left(\frac{d \bar{G}-d \bar{G}^{*}}{\bar{y}_{0}}\right) \frac{\alpha \theta(2-\alpha) \gamma_{17}+(\alpha-1) \gamma_{8}\left(\gamma_{15}+\gamma_{11}\right)}{2 \gamma_{8} \gamma_{11}}+\left(\frac{1+\varepsilon(1+2 \bar{r})}{2 \varepsilon(1+\bar{r})}\right) \frac{d \bar{G}^{W}}{\bar{y}_{0}} \\
& \tilde{y}=\left(\frac{d \bar{G}-d \bar{G}^{*}}{2 \bar{y}_{0}}\right) \frac{(\alpha-1) \gamma_{0} \gamma_{8} \gamma_{11}-(2-\alpha)(1-\alpha+\alpha \theta) \gamma_{18}}{\alpha \gamma_{0} \gamma_{8} \gamma_{11}}+\frac{d \bar{G}^{W}}{2 \bar{y}_{0}} \\
& \tilde{y}^{*}=-\left(\frac{d \bar{G}-d \bar{G}^{*}}{2 \bar{y}_{0}}\right) \frac{(\alpha-1) \gamma_{0} \gamma_{8} \gamma_{11}-(2-\alpha)(1-\alpha+\alpha \theta) \gamma_{18}}{\alpha \gamma_{0} \gamma_{8} \gamma_{11}}+\frac{d \bar{G}^{W}}{2 \bar{y}_{0}} \\
& \hat{C}=\left(\frac{d \bar{G}-d \bar{G}^{*}}{\bar{y}_{0}}\right) \frac{\gamma_{15}}{2 \gamma_{11}}-\left(\frac{\varepsilon-1}{2 \varepsilon(1+\bar{r})}\right) \frac{d \bar{G}^{W}}{\bar{y}_{0}} \\
& \hat{C}^{*}=-\left(\frac{d \bar{G}-d \bar{G}^{*}}{\bar{y}_{0}}\right) \frac{\gamma_{15}}{2 \gamma_{11}}-\left(\frac{\varepsilon-1}{2 \varepsilon(1+\bar{r})}\right) \frac{d \bar{G}^{W}}{\bar{y}_{0}} \\
& \tilde{C}=\left(\frac{d \bar{G}-d \bar{G}^{*}}{2 \bar{y}_{0}}\right)\left(\frac{\gamma_{15}}{\gamma_{11}}+\frac{(1-\alpha)\left(\gamma_{0} \gamma_{17}+\gamma_{18}\right)}{\gamma_{0} \gamma_{8} \gamma_{11}}\right)-\frac{d \bar{G}^{W}}{2 \bar{y}_{0}} \\
& \tilde{C}^{*}=-\left(\frac{d \bar{G}-d \bar{G}^{*}}{2 \bar{y}_{0}}\right)\left(\frac{\gamma_{15}}{\gamma_{11}}+\frac{(1-\alpha)\left(\gamma_{0} \gamma_{17}+\gamma_{18}\right)}{\gamma_{0} \gamma_{8} \gamma_{11}}\right)-\frac{d \bar{G}^{W}}{2 \bar{y}_{0}} \\
& \hat{r}=(1-\alpha)\left(\frac{d \bar{G}-d \bar{G}^{*}}{\bar{y}_{0}}\right) \frac{\gamma_{0} \gamma_{17}+\gamma_{18}}{2(1-\beta) \gamma_{0} \gamma_{8} \gamma_{11}}-\left(\frac{1+\bar{r} \varepsilon}{2 \varepsilon(1+\bar{r})(1-\beta)}\right) \frac{d \bar{G}^{W}}{\bar{y}_{0}} \\
& \hat{r}^{*}=-(1-\alpha)\left(\frac{d \bar{G}-d \bar{G}^{*}}{\bar{y}_{0}}\right) \frac{\gamma_{0} \gamma_{17}+\gamma_{18}}{2(1-\beta) \gamma_{0} \gamma_{8} \gamma_{11}}-\left(\frac{1+\bar{r} \varepsilon}{2 \varepsilon(1+\bar{r})(1-\beta)}\right) \frac{d \bar{G}^{W}}{\bar{y}_{0}}
\end{aligned}
$$




\section{Permanent Productivity Shock}

\section{$\underline{\text { Cross-Country Differences }}$}

$$
\begin{aligned}
& \hat{E}=\frac{\gamma_{21}}{\gamma_{8} \gamma_{11}}\left(\tilde{\kappa}-\tilde{\kappa}^{*}\right) \\
& \tilde{E}=\frac{\bar{r} \gamma_{8} \gamma_{20}+\gamma_{21}(1+\bar{r} \varepsilon(2-\alpha))}{\gamma_{8} \gamma_{11}}\left(\tilde{\kappa}-\tilde{\kappa}^{*}\right) \\
& \tilde{t}=\frac{\gamma_{24}}{\gamma_{8} \gamma_{11} \gamma_{23}}\left(\tilde{\mathbf{\kappa}}-\tilde{\mathbf{\kappa}}^{*}\right) \\
& \hat{C}-\hat{C}^{*}=\frac{\gamma_{20}}{\gamma_{11}}\left(\tilde{\boldsymbol{\kappa}}-\tilde{\boldsymbol{\kappa}}^{*}\right) \\
& \tilde{C}-\tilde{C}^{*}=\frac{\gamma_{25}}{\alpha \gamma_{8} \gamma_{11} \gamma_{23}}\left(\tilde{\mathbf{\kappa}}-\tilde{\mathbf{\kappa}}^{*}\right) \\
& \frac{d \bar{B}}{\bar{y}_{0}}=\frac{(2-\alpha) \gamma_{22}}{2 \gamma_{8} \gamma_{11}}\left(\tilde{\mathbf{\kappa}}-\tilde{\kappa}^{*}\right) \\
& \hat{y}-\hat{y}^{*}=\frac{\alpha(2-\alpha) \theta \gamma_{21}-(\alpha-1) \gamma_{8} \gamma_{20}}{\gamma_{8} \gamma_{11}}\left(\tilde{\kappa}-\tilde{\kappa}^{*}\right) \\
& \tilde{y}-\tilde{y}^{*}=\frac{(1-\alpha) \gamma_{8} \gamma_{11} \gamma_{23}-(2-\alpha)(1-\alpha+\alpha \theta) \gamma_{24}}{\alpha \gamma_{8} \gamma_{11} \gamma_{23}}\left(\tilde{\kappa}-\tilde{\kappa}^{*}\right) \\
& \hat{r}-\hat{r}^{*}=(1-\alpha)\left(\frac{\gamma_{24}+\gamma_{21} \gamma_{23}}{(1-\beta) \gamma_{8} \gamma_{11} \gamma_{23}}\right)\left(\tilde{\mathbf{\kappa}}-\tilde{\boldsymbol{\kappa}}^{*}\right) \\
& \tilde{P}-\tilde{P}^{*}=-\frac{\gamma_{25}}{\alpha \varepsilon \gamma_{8} \gamma_{11} \gamma_{23}}\left(\tilde{\kappa}-\tilde{\kappa}^{*}\right)
\end{aligned}
$$




\section{Country Levels}

$$
\begin{aligned}
& \hat{C}=\frac{\gamma_{20}}{2 \gamma_{11}}\left(\tilde{\kappa}-\tilde{\kappa}^{*}\right)+\frac{1-\varepsilon}{2 \varepsilon(1+\bar{r})} \tilde{\kappa}^{W} \\
& \hat{C}^{*}=-\frac{\gamma_{20}}{2 \gamma_{11}}\left(\tilde{\kappa}-\tilde{\mathbf{\kappa}}^{*}\right)+\frac{1-\varepsilon}{2 \varepsilon(1+\bar{r})} \tilde{\kappa}^{W} \\
& \tilde{C}=\frac{\gamma_{25}}{2 \alpha \gamma_{8} \gamma_{11} \gamma_{23}}\left(\tilde{\kappa}-\tilde{\kappa}^{*}\right)-\frac{\tilde{\kappa}^{W}}{2} \\
& \tilde{C}^{*}=-\frac{\gamma_{25}}{2 \alpha \gamma_{8} \gamma_{11} \gamma_{23}}\left(\tilde{\mathbf{\kappa}}-\tilde{\mathbf{\kappa}}^{*}\right)-\frac{\tilde{\kappa}^{W}}{2} \\
& \hat{y}=\frac{\alpha(2-\alpha) \theta \gamma_{21}-(\alpha-1) \gamma_{8} \gamma_{20}}{2 \gamma_{8} \gamma_{11}}\left(\tilde{\boldsymbol{\kappa}}-\tilde{\boldsymbol{\kappa}}^{*}\right)+\left(\frac{1-\varepsilon}{2 \varepsilon(1+\bar{r})}\right) \tilde{\boldsymbol{\kappa}}^{W} \\
& \hat{y}^{*}=-\frac{\alpha(2-\alpha) \theta \gamma_{21}-(\alpha-1) \gamma_{8} \gamma_{20}}{2 \gamma_{8} \gamma_{11}}\left(\tilde{\kappa}-\tilde{\kappa}^{*}\right)+\left(\frac{1-\varepsilon}{2 \varepsilon(1+\bar{r})}\right) \tilde{\kappa}^{W} \\
& \tilde{y}=\frac{(1-\alpha) \gamma_{8} \gamma_{11} \gamma_{23}-(2-\alpha)(1-\alpha+\alpha \theta) \gamma_{24}}{2 \alpha \gamma_{8} \gamma_{11} \gamma_{23}}\left(\tilde{\kappa}-\tilde{\kappa}^{*}\right)-\frac{\tilde{\kappa}^{W}}{2} \\
& \tilde{y}^{*}=-\frac{(1-\alpha) \gamma_{8} \gamma_{11} \gamma_{23}-(2-\alpha)(1-\alpha+\alpha \theta) \gamma_{24}}{2 \alpha \gamma_{8} \gamma_{11} \gamma_{23}}\left(\tilde{\kappa}-\tilde{\kappa}^{*}\right)-\frac{\tilde{\kappa}^{W}}{2} \\
& \tilde{P}=-\frac{\gamma_{25}}{2 \alpha \varepsilon \gamma_{8} \gamma_{11} \gamma_{23}}\left(\tilde{\kappa}-\tilde{\kappa}^{*}\right)+\frac{\tilde{\kappa}^{W}}{2 \varepsilon} \\
& \tilde{P}^{*}=\frac{\gamma_{25}}{2 \alpha \varepsilon \gamma_{8} \gamma_{11} \gamma_{23}}\left(\tilde{\kappa}-\tilde{\kappa}^{*}\right)+\frac{\tilde{\kappa}^{W}}{2 \varepsilon} \\
& \hat{r}=(1-\alpha)\left(\frac{\gamma_{24}+\gamma_{21} \gamma_{23}}{2(1-\beta) \gamma_{8} \gamma_{11} \gamma_{23}}\right)\left(\tilde{\boldsymbol{\kappa}}-\tilde{\boldsymbol{\kappa}}^{*}\right)-\left(\frac{1+\bar{r} \varepsilon}{2 \varepsilon(1+\bar{r}) \bar{r} \beta}\right) \tilde{\kappa}^{W} \\
& \hat{r}^{*}=-(1-\alpha)\left(\frac{\gamma_{24}+\gamma_{21} \gamma_{23}}{2(1-\beta) \gamma_{8} \gamma_{11} \gamma_{23}}\right)\left(\tilde{\kappa}-\tilde{\kappa}^{*}\right)-\left(\frac{1+\bar{r} \varepsilon}{2 \varepsilon(1+\bar{r}) \bar{r} \beta}\right) \tilde{\kappa}^{W}
\end{aligned}
$$




\section{Definitions}

$$
\begin{array}{lrl}
\gamma_{0} \equiv(2-\alpha)(\alpha \theta+1)+\alpha(\alpha-1) & \gamma_{1} \equiv 1-\alpha+\varepsilon+\bar{r} \varepsilon^{2}(2-\alpha) \\
\gamma_{2} \equiv(\varepsilon-1)(\alpha-1) & \gamma_{3} \equiv 2(1+\theta-\alpha) \\
\gamma_{4} \equiv(1-\alpha)\left(2 \theta(2-\alpha)-\gamma_{3}\right) & \gamma_{5} \equiv(2-\alpha) \bar{r}(\theta+1) \\
\gamma_{6} \equiv(\alpha-1) \gamma_{3}+(\alpha \theta-1) \gamma_{5} & \gamma_{7} \equiv \gamma_{0} \gamma_{1}+\alpha(1-\alpha) \gamma_{2} \\
\gamma_{8} \equiv \gamma_{0} \gamma_{6}+\alpha(1-\alpha) \gamma_{4} & \gamma_{9} \equiv \gamma_{0} \gamma_{8}(1+\bar{r} \varepsilon) \\
\gamma_{10} \equiv \gamma_{0}\left(\gamma_{3}+\gamma_{5}\right)-\alpha \gamma_{4} & \gamma_{11} \equiv \gamma_{7} \gamma_{10}+\gamma_{9}+\alpha \gamma_{2} \gamma_{8} \\
\gamma_{12}=\gamma_{10}(\alpha \theta-1)-\gamma_{8} & \gamma_{13}=\theta(1+\alpha \theta)+(1-\alpha) \\
\gamma_{14} \equiv \gamma_{5}+\theta-2 \alpha+3 & \gamma_{15}=(1-\alpha)\left(\gamma_{2} \gamma_{8}-\gamma_{4} \gamma_{7}\right)-\gamma_{0} \gamma_{7} \gamma_{14} \\
\gamma_{16} \equiv \gamma_{0} \gamma_{14}+(1-\alpha) \gamma_{4} & \gamma_{17} \equiv \gamma_{10} \gamma_{15}+\gamma_{11} \gamma_{16} \\
\gamma_{18} \equiv \alpha \gamma_{8} \gamma_{15}+(1-\alpha)\left(\alpha \gamma_{17}-\gamma_{8} \gamma_{11}\right) & \gamma_{19} \equiv \gamma_{4}-\gamma_{0}(\theta-1) \\
\gamma_{20} \equiv \gamma_{7} \gamma_{19}-\gamma_{8} \gamma_{2} & \gamma_{21} \equiv \gamma_{10} \gamma_{20}-\gamma_{11} \gamma_{19} \\
\gamma_{22} \equiv \gamma_{21}(\alpha \theta-1)-\gamma_{8} \gamma_{20} & \gamma_{23} \equiv 2(2-\alpha)(\theta+1)(\alpha(\theta-1)+1) \\
\gamma_{24} \equiv \alpha \gamma_{5} \gamma_{22}+\gamma_{8} \gamma_{11}\left(\gamma_{3}-\alpha(\theta-1)\right) & \gamma_{25} \equiv(2-\alpha)(\alpha \theta+1) \gamma_{24}-\gamma_{23} \gamma_{8} \gamma_{11}
\end{array}
$$

